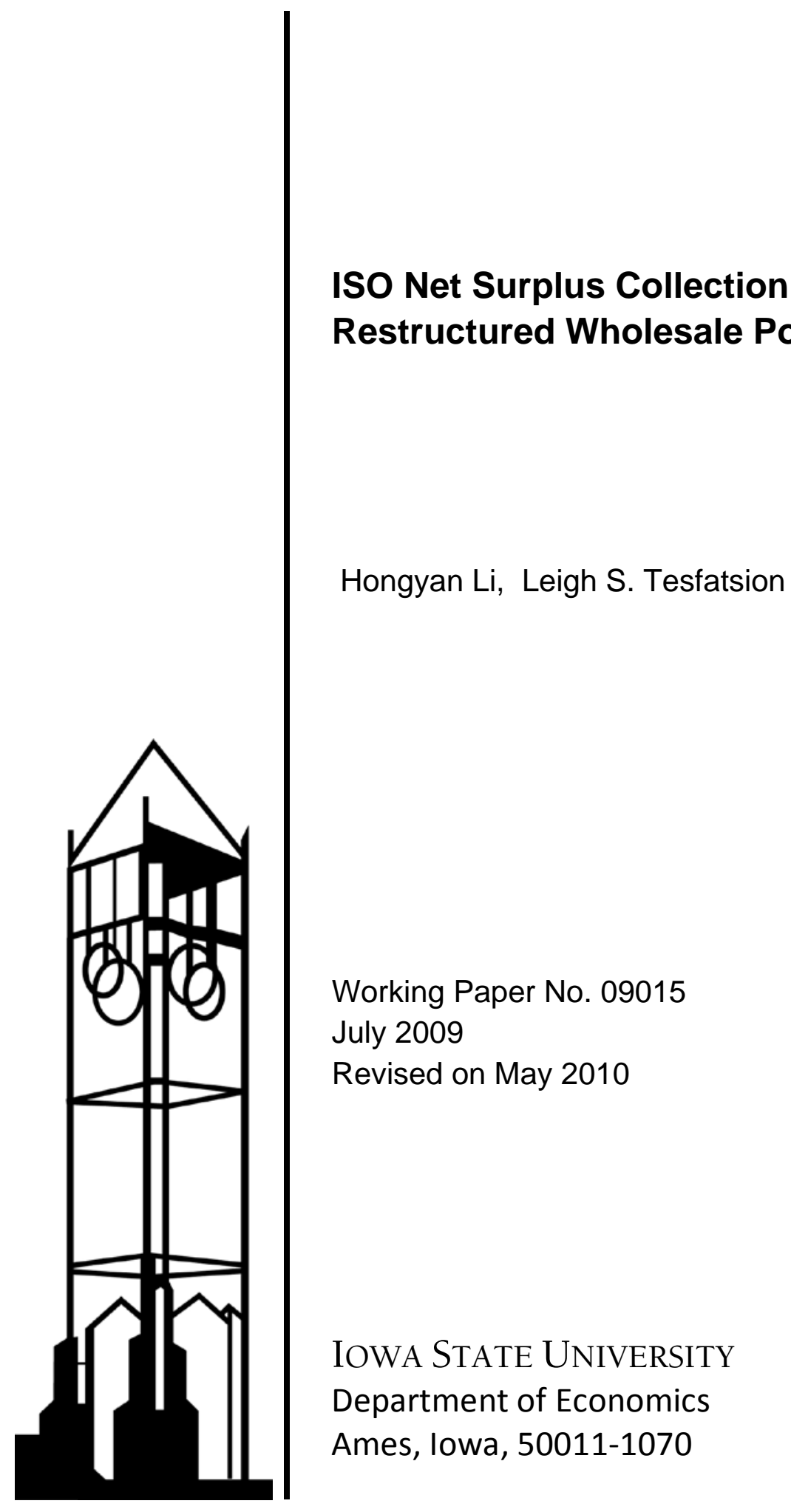

lowa State University does not discriminate on the basis of race, color, age, religion, national origin, sexual orientation, gender identity, sex, marital status, disability, or status as a U.S. veteran. Inquiries can be directed to the Director of Equal Opportunity and Diversity, 3680 Beardshear Hall, (515) 294-7612. 


\title{
ISO Net Surplus Collection and Allocation in Wholesale Power Markets under LMP
}

\author{
Hongyan Li, Member, IEEE, and Leigh Tesfatsion, Member, IEEE
}

\begin{abstract}
This study uses 5-bus and 30-bus test cases to explore ISO net surplus (congestion rent) collections and allocations in wholesale power markets with grid congestion managed by locational marginal prices (LMPs). Price-sensitivity of demand and generator learning capabilities are taken as experimental treatment factors. A key finding is that conditions resulting in greater generator capacity withholding, hence higher and more volatile LMPs, also result in greater ISO net surplus collections that can be substantial in size. A key conclusion is that ISO net surplus collections should be used pro-actively to mitigate the conditions encouraging generator capacity withholding and hence high and volatile LMPs rather than to provide ex post support for LMP payment offsets and LMP volatility risk hedging as is currently the norm.
\end{abstract}

Index Terms-Wholesale power market, locational marginal pricing, ISO net surplus (congestion rent), efficiency, welfare, learning, demand-bid price sensitivity, AMES Testbed

\section{INTRODUCTION}

A S elaborated in [1], over $50 \%$ of electric power generation in the U.S. is now traded at wholesale using centrally managed locational marginal prices (LMPS). Under this pricing scheme, a not-for-profit Independent System Operator (ISO) uses the solutions of suitably formulated bid/offer-based optimal power flow (OPF) problems to price electric power in accordance with the location and timing of its injection into or withdrawal from the transmission grid.

Roughly, an LMP at a particular grid location is the least cost to the system of servicing an additional increment of demand (load) at that location. ${ }^{1}$ Congestion arising on any grid branch necessarily results in separation between the LMPs at two or more pricing locations. Ideally, persistent LMP separation should encourage energy supply to be offered when and where it has the greatest value, encourage energy demand to be bid when and where it can be serviced most cheaply, and signal where transmission enhancements should be made to relieve grid congestion in the longer run [4].

Latest revision: 30 May 2010. To appear in the IEEE Transactions on Power Systems, Vol. 26. This work has been supported in part by the National Science Foundation under Grant NSF-0527460 and by grants from the ISU Electric Power Research Center.

Hongyan Li, Consulting Engineer, ABB Inc., Raleigh, North Carolina, and Leigh Tesfatsion (corresponding author: tesfatsi@iastate.edu), Professor of Economics, Mathematics, and Electrical and Computer Engineering, Iowa State University, Ames, IA 50011-1070 USA.

${ }^{1}$ More precisely, as carefully explained in [2], the LMP at a particular bus $k$ is the dual variable (shadow price) corresponding to the balance constraint ensuring the satisfaction of Kirchhoff's current law at bus $k$. Consequently, given certain regularity conditions, it can be expressed as the change in the optimized OPF objective function with respect to a change in fixed demand at bus $k$. As discussed and illustrated in [3], LMPs are conceptually distinct from "competitive market clearing prices."
As is well-known, however, given branch and generation capacity limits, the physical laws regulating the flow of power on non-radial transmission grids can result in counter-intuitive LMP separation outcomes ( [5], [6, Chp. 6]). For example, LMPs at the two ends of a branch can separate without the branch being congested, power can flow from higher to lower price locations, and the price at a load-only location can be strictly higher or strictly lower than the marginal cost of any marginal (non-capacity-constrained) generation unit.

Another important LMP separation outcome is the creation of a net earnings stream that is distinct from buyer and seller net surplus. ${ }^{2}$ When LMPs separate across the grid, the prices paid by wholesale buyers can diverge from the prices paid to wholesale sellers. The difference between total buyer payments and total seller receipts is a net earnings stream collected and allocated by the ISO. Hereafter these ISO collections will be referred to as ISO net surplus. ${ }^{3}$

Previous research has shown that ISO net surplus is necessarily non-negative under standard DC-OPF formulations for the determination of LMP and dispatch levels in ISOmanaged wholesale power markets; see [8, Prop. 2.1]. Simulation findings in [5, Fig. 11] demonstrate the strong sensitivity of ISO net surplus to variations in the limits constraining branch power flows. To date, however, the sensitivity of ISO net surplus to variations in more general structural conditions does not appear to have been systematically examined.

This study uses the AMES Wholesale Power Market Testbed [9] to investigate how ISO net surplus varies in response to changes in the price-sensitivity of demand and the learning capabilities of generation companies in ISO-operated wholesale power markets with congestion managed by LMP. Also investigated are the effects of these changes on market

\footnotetext{
${ }^{2}$ Roughly, net surplus refers to benefits minus costs. This standard economic concept is more rigorously defined in Section II-B, below; see also the detailed discussions in [3], [7]. Economists distinguish types of net surplus, e.g., buyer versus seller, by which type of agent initially collects the net surplus, regardless of its subsequent allocation.

${ }^{3}$ When grids are modeled as lossless, LMP separation only arises in the presence of congestion and the net surplus collected and allocated by the ISO is then sometimes referred to as congestion rent. Another term occasionally used is merchandising surplus. In economics, however, "rent" has the precise meaning of a payment directly received by a resource in excess of the amount needed to retain that resource in its current productive use; and the qualifier "merchandising" suggests collection through merchant trades (i.e., through purely private business transactions). The use of the terms "congestion rent" and "merchandising surplus" are therefore avoided in this study.
} 
efficiency and the welfare of market participants. ${ }^{4}$ In addition, we consider the social efficiency and welfare implications of the allocation of ISO net surplus collections to other parties. ${ }^{5}$

Standard market efficiency analysis considers the extent to which buyers and sellers participating in a single market succeed in extracting maximum possible total net surplus from this market. This analysis is increasingly being applied to the study of power markets; see, e.g., [10]- [13]. However, the standard market efficiency analysis does not consider the possibility that an agency tasked with clearing the market, here the ISO, is able to collect net surplus along with buyers and sellers. This feature appears to raise potential conflict of interest issues even if ISOs are required to allocate their net surplus collections to other parties. Moreover, the standard market efficiency analysis does not consider the more comprehensive issues of social efficiency and welfare.

In AMES(V2.05), used in this study, the ISO manages a day-ahead energy market participated in by wholesale buyers called Load-Serving Entities (LSES) and wholesale sellers called Generation Companies (GenCos). As explained more carefully in Section II and Appendix A, the ISO uses standard bid/offer-based DC-OPF to determine hourly LMP and dispatch levels for this market.

As detailed in Section III, systematic experiments are conducted using multi-period versions of a commonly used 5-bus ISO training case and a standard IEEE 30-bus test case. Two treatment factors are selected for the experimental design. The first treatment factor is the degree to which the LSEs report fixed versus price-sensitive demand bids to the ISO for the day-ahead energy market, an increasingly important issue as pressures increase for more demand response in wholesale power markets [14]-[16]. The second treatment factor is the degree to which the GenCos can learn to report higher-thantrue marginal costs to the ISO for the day-ahead energy market, i.e., to exercise economic capacity withholding. Even with $100 \%$ fixed demand, economic capacity withholding can cause market inefficiency (reductions in total net surplus) if it results in the out-of-merit-order dispatch of costlier generation. Moreover, it can also affect the distribution of total net surplus among LSEs, GenCos, and the ISO.

Experimental findings are reported in Section IV. Some amount of congestion arises in all treatments, leading to LMP separation. However, all treatment outcomes are carefully compared against benchmark cases, so that changes in market outcomes can be fully attributed to changes in treatment factors. A key finding is that ISO and GenCo net surplus are both enhanced in treatments unfavorable to market efficiency. Specifically, price-sensitivity and learning treatments

\footnotetext{
${ }^{4}$ In standard economic usage, efficiency refers to non-wastage of resources typically measured by the size of the total net surplus resulting from resource usage. In contrast, welfare refers to the well-being of persons often practically measured by the distribution of the total net surplus resulting from resource usage.

${ }^{5}$ Economists standardly measure social efficiency in terms of the current and future non-wastage of resources for a society as a whole. Social efficiency is distinct from social welfare, typically measured in terms of the current and future well-being of the people populating a society in their roles as consumers of final goods and services. Social efficiency is necessary but not sufficient for the maximization of social welfare, since the latter requires an appropriate resource distribution in addition to resource non-wastage.
}

resulting in greater GenCo economic capacity withholding, hence higher and more volatile LMPs, also result in greater ISO and GenCo net surplus collections. These collections are particularly large when LSE demand bids take the form of $100 \%$ fixed (price-insensitive) demands.

All else equal, the LSEs are the big losers in the treatments unfavorable to market efficiency. For example, with $100 \%$ fixed demand, moving from no-learning to learning GenCos results in a substantial increase in both ISO and GenCo net surplus even though total net surplus decreases due to out-of-merit-order generation dispatch. This decrease in total net surplus reflects the substantial drop in LSE net surplus. However, if LSEs resell their wholesale energy purchases to downstream retail customers at regulated prices adjusted in step with wholesale power prices, then LSEs can recoup their losses. In this case the costs of the resource wastage are borne by retail consumers rather than by wholesale power market participants.

As discussed in Section V, annual reports for U.S. wholesale power markets operating under LMP indicate that ISO net surplus collections are indeed sizable in some regions. Although there is no mention in these reports of any legal obligation to allocate these collections, the reports indicate they are typically allocated as revenues to holders of financial transmission rights (including speculators as well as GenCos and LSEs), with some residual use as payment offsets to LSEs. Unfortunately, although the reporting of ISO net surplus collections and allocations has improved over the past ten years, ${ }^{6}$ data on these activities are still not presented with sufficient disaggregation and consistency across reports to permit detailed empirical analyses and cross-ISO comparisons.

The final Section VI discusses the overall policy implications of our experimental findings. A brief summary of these implications is as follows.

First, conditions resulting in greater GenCo capacity withholding, hence higher and more volatile LMPs, also result in greater ISO net surplus collections that can be substantial in size. These conditions include lower price-sensitivity of demand and increased GenCo learning capabilities.

This positive correlation between conditions conducive to GenCo capacity withholding and the size of ISO net surplus collections is troublesome, not because there is abuse in current ISO practice, but because of the potential for abuse over time. For example, purely on financial grounds, ISOs have an incentive to perpetuate low price-sensitivity of demand because it provides a revenue stream whose precise allocation is at the discretion of the ISO. An immediate step that could be taken to alleviate concerns here is increased transparency and consistency in the public reporting of ISO activities, a step strongly advocated in [18, Section V.B.2].

Second, ISO net surplus collections should not simply be used to help support LMP volatility risk hedging or to offset high LMP payments by wholesale power market participants, as is currently the norm. These ex post compensatory measures do little to alter the underlying conditions that encourage

\footnotetext{
${ }^{6}$ See [17] for a heroic attempt in 2001 to estimate the ISO net surplus (congestion rent) collected by the ISOs in New York, California, and PJM.
} 


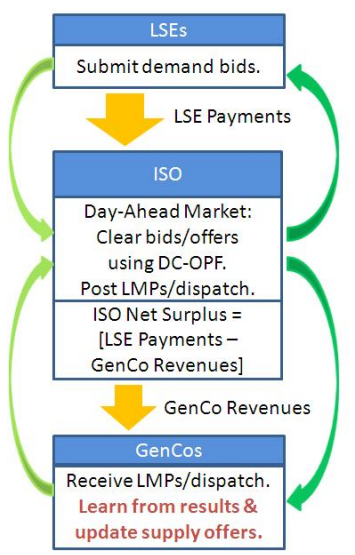

Fig. 1. AMES day-ahead energy market activities during each day D.

GenCo capacity withholding and that therefore contribute to higher and more volatile LMPs. Moreover, they do nothing to rectify any net surplus losses experienced by retail consumers as a result of these conditions.

Rather, ISO net surplus collections should instead be used pro-actively to help mitigate the conditions that encourage GenCo capacity withholding. For example, they might be used to properly incentivize socially beneficial reductions in congestion [13], or to support demand-response, demand dispatch, and dynamic pricing initiatives [15], [16]. Another possible use might be to support the timely gathering and release of market data to appropriate outside parties (e.g., state commissions, university researchers) enabling additional checks on the exercise of GenCo market power.

\section{AMES TESTBED}

The latest version of AMES (Agent-based Modeling of Electricity Systems) can be freely downloaded either at [19] or [20]. Section II-A summarizes the key features of Version 2.05 of AMES, used in this study. These key features reflect, in simplified form, day-ahead energy market operations in the MISO ( [21], [22]) and ISO-NE [23]; cf. Fig. 1. Section II-B provides quantitative definitions for the net surplus amounts collected by the AMES LSEs, GenCos, and ISO, and for market efficiency measured in terms of total net surplus.

\section{A. Overview of Key AMES Features}

The AMES(V2.05) wholesale power market operates over an $\mathrm{AC}$ transmission grid starting with hour 00 of day 1 and continuing through hour 23 of a user-specified maximum day. AMES includes an Independent System Operator (ISO) and a collection of energy traders consisting of $J$ Load-Serving Entities (LSEs) and I Generation Companies (GenCos) distributed across the buses of the transmission grid.

The objective of the not-for-profit ISO is the maximization of Total Net Surplus (TNS) subject to transmission constraints and GenCo operating capacity limits. In an attempt to attain this objective, the ISO operates a day-ahead energy market settled by means of LMP.
The welfare of each LSE $j$ is measured by the net earnings it secures for itself through the purchase of power in the dayahead market and the resale of this power to its retail customers. During the morning of each day D, each LSE $j$ reports a demand bid to the ISO for the day-ahead market for day D+1. Each demand bid consists of two parts: fixed demand (i.e., a 24-hour load profile) to be sold downstream at a regulated price $r$ to its retail customers with fixed-price contracts; and 24 price-sensitive inverse demand functions, one for each hour, reflecting the price-sensitive demand (willingness to pay) of its retail customers with dynamic-price contracts. ${ }^{7}$

The objective of each GenCo $i$ is to secure for itself the highest possible net earnings each day through the sale of power in the day-ahead market. During the morning of each day $\mathrm{D}$, each GenCo $i$ uses its current action choice probabilities to choose a supply offer from its action domain $\mathrm{AD}_{i}$ to report to the ISO for use in all 24 hours of the dayahead market for day $\mathrm{D}+1 .{ }^{8}$ Each supply offer in $\mathrm{AD}_{i}$ consists of a linear marginal cost function defined over an operating capacity interval. GenCo $i$ 's ability to vary its choice of a supply offer from $\mathrm{AD}_{i}$ permits it to adjust the ordinate/slope of its reported marginal cost function and/or the upper limit of its reported operating capacity interval in an attempt to increase its daily net earnings.

After receiving demand bids from LSEs and supply offers from GenCos during the morning of day D, the ISO determines and publicly posts hourly bus LMP levels as well as LSE cleared demands and GenCo dispatch levels for the day-ahead market for day D+1. These hourly outcomes are determined via Security-Constrained Economic Dispatch (SCED) formulated as bid/offer-based DC Optimal Power Flow (DC-OPF) problems with approximated TNS objective functions based on reported rather than true GenCo costs. ${ }^{9}$

At the end of each day D the ISO settles the day-ahead market for day $\mathrm{D}+1$ by receiving all purchase payments from LSEs and making all sale payments to GenCos based on the LMPs for the day-ahead market for day D+1, collecting any difference as ISO net surplus. As will be clarified in Section II-B, this ISO net surplus is guaranteed to be nonnegative

\footnotetext{
${ }^{7}$ The LSEs in AMES(V2.05) have no learning capabilities; LSE demand bids are user-specified at the beginning of each simulation run. However, as explained more carefully in [9], AMES(V2.05) includes a learning module, JReLM, that can be used to implement a wide variety of stochastic reinforcement learning methods for decision-making agents. Extension to include LSE learning is planned for future AMES releases.

${ }^{8}$ Whether GenCos are permitted to report only one supply offer or 24 supply offers for use in the day-ahead energy market varies from one energy region to another. For example, the ISO-NE permits only one supply offer whereas MISO permits 24 separate supply offers. Baldick and Hogan [24, pp. 18-20] conjecture that imposing limits on the ability of GenCos to report distinct hourly supply offers could reduce their ability to exercise market power.

${ }^{9} \mathrm{~A}$ technical presentation of the bid/offer-based DC-OPF problem formulation for the ISO in AMES(V2.05) is provided in Appendix A. The solutions to these DC-OPF problems takes the form of "supply function equilibria" rather than market clearing outcomes based on single-point bids and offers; see [25]. As will be seen in Section II-B, the GenCos do not incur start-up/shut-down or no-load costs and do not face ramp rate constraints. Consequently, the ISO in AMES(V2.05) does not undertake Security-Constrained Unit Commitment $(S C U C)$. In future AMES versions the user will be able to specify these types of unit commitment costs and constraints for GenCos and to have the ISO undertake SCUC and SCED in tandem to determine GenCo commitments and dispatch levels.
} 
and, under congested grid conditions, will typically be strictly positive due to the separation of bus LMPs and the dispersion of the GenCos and LSEs across the various bus locations.

Each GenCo $i$ at the end of each day D uses a stochastic reinforcement learning algorithm to update the action choice probabilities currently assigned to the supply offers in its action domain $\mathrm{AD}_{i}$, taking into account its day-D settlement payment ("reward"). In particular, if GenCo $i$ 's supply offer on day D results in a relatively good reward, GenCo $i$ increases the probability it will choose to report this same supply offer on day $\mathrm{D}+1$, and conversely. ${ }^{10}$

There are no system disturbances (e.g., weather changes) or shocks (e.g., line outages). Consequently, the dispatch levels determined on each day $\mathrm{D}$ for the day-ahead energy market for day $\mathrm{D}+1$ are carried out as planned without need for settlement of differences in the real-time energy market for day $\mathrm{D}+1$.

\section{B. Total Net Surplus and Market Efficiency}

In AMES(V2.05), total net surplus (TNS) is the sum of LSE, GenCo, and ISO net surplus. As detailed in Appendix A, for each hour $\mathrm{H}$ of the day-ahead energy market the ISO attempts to solve a standard bid/offer-based DC-OPF problem involving the maximization of TNS subject to power-flow balance constraints, transmission branch limits, and GenCo capacity constraints. ${ }^{11}$ However, in GenCo learning treatments the ISO has to construct its TNS objective function using reported rather than true GenCo costs.

For later use in Sections III and IV, this subsection presents the general parameterized AMES(V2.05) formulations for LSE demand bids and GenCo supply offers as well as the LSE, GenCo, and ISO total net surplus amounts realized during each day $\mathrm{D}$. The precise parameter value settings used in specific experiments are explained in Section III below.

For each day D, LSE $j$ 's demand bid for hour $\mathrm{H}$ of the day-ahead market for day $\mathrm{D}+1$ consists of a fixed demand for power, $\mathrm{p}_{L j}^{F}(\mathrm{H}, \mathrm{D})$, to be sold downstream at a regulated price $r(\$ / \mathrm{MWh})$ to its retail customers with fixed-price contracts, and a linear price-sensitive inverse demand function

$$
\mathrm{F}_{j H D}\left(p_{L j}^{S}\right)=\mathrm{c}_{j}(H, D)-2 \mathrm{~d}_{j}(H, D) p_{L j}^{S} \quad(\$ / M W h)
$$

defined over a power purchase interval

$$
0 \leq p_{L j}^{S} \leq \operatorname{SLMax}_{j}(H, D) \quad(M W)
$$

The expression $\mathrm{F}_{j H D}\left(\mathrm{p}_{L j}^{S}\right)$ in (1) denotes LSE $j$ 's purchase reservation value for energy evaluated at $\mathrm{p}_{L j}^{S}$, i.e., the maximum dollar amount it is truly willing to pay per MWh, which in turn reflects the willingness-to-pay of its retail customers with dynamic-price contracts.

Suppose LSE $j$, located at bus $k(j)$, is cleared at a total demand level $\mathrm{p}_{L j}(\mathrm{H}, \mathrm{D})=\left[\mathrm{p}_{L j}^{F}(\mathrm{H}, \mathrm{D})+\mathrm{p}_{L j}^{S}(\mathrm{H}, \mathrm{D})\right]$ at price $\mathrm{LMP}_{k(j)}(\mathrm{H}, \mathrm{D})$ for hour $\mathrm{H}$ of the day-ahead market for day

\footnotetext{
${ }^{10} \mathrm{~A}$ complete technical description of the stochastic reinforcement learning algorithm used for GenCo learning is provided in Appendix B.

${ }^{11}$ As will be seen below, when all demand is fixed (i.e., price insensitive), the maximization of TNS is equivalent to the minimization of GenCo total avoidable costs.
}

$\mathrm{D}+1$. The payments of LSE $j$ for all 24 hours of day D+1, settled at the end of day $\mathrm{D}$, are

$$
\operatorname{Pay}_{j}(D)=\sum_{H=00}^{23} L M P_{k(j)}(H, D) \cdot p_{L j}(H, D)
$$

Using standard market efficiency analysis [3], the net surplus accruing to the "last" MW of power sold by LSE $j$ to its dynamic-price retail customers, evaluated at any total sale quantity $p$, is given by $\left[F_{j H D}(p)-\pi\right]+\left[\pi-L M P_{k(j)}(H, D)\right]$, where $\pi$ denotes the price charged by LSE $j$ for this last MW. The first bracketed term is the net surplus portion accruing to the retail customers and the second bracketed term is the net surplus portion accruing to LSE $j$. For simplicity, it will hereafter be supposed that LSE $j$ is able to extract all net surplus from its dynamic-price retail customers by charging these customers their maximum willingness to pay for each purchased MW, i.e., by setting $\pi=F_{j H D}(p)$ at each power level $p .{ }^{12}$ It follows that the gross surplus for LSE $j$ realized on day $\mathrm{D}$ is given by the revenue (\$) amount

$$
G S_{j}(D)=\sum_{H=00}^{23}\left[r \cdot p_{L j}^{F}(H, D)+\int_{0}^{p_{L j}^{S}(H, D)} \mathrm{F}_{j H D}(p) d p\right]
$$

The LSE net surplus realized on day D is then

$$
\operatorname{LSENetSur}(D)=\sum_{j=1}^{J}\left[\operatorname{GS}_{j}(D)-\operatorname{Pay}_{j}(D)\right]
$$

For each day D, the supply offer chosen by GenCo $i$ to report to the ISO for use in each hour $\mathrm{H}$ of the day-ahead market for day D+1 consists of a linear reported marginal cost function

$$
\operatorname{MC}_{i D}^{R}\left(p_{G i}\right)=\mathrm{a}_{i}^{R}(D)+2 \mathbf{b}_{i}^{R}(D) p_{G i} \quad(\$ / M W h)
$$

defined over an operating capacity interval

$$
\mathrm{Cap}_{i}^{L} \leq p_{G i} \leq \operatorname{Cap}_{i}^{U}(M W)
$$

for the generation of power $\mathrm{p}_{G i}$. The expression $\mathrm{MC}_{i D}^{R}\left(\mathrm{p}_{G i}\right)$ in (6) denotes GenCo $i$ 's reported sale reservation value for energy evaluated at $\mathrm{p}_{G i}$, i.e., the minimum dollar amount it reports it is willing to accept per MWh. The reported marginal cost functions (6) can lie either on or above GenCo i's true marginal cost function

$$
\operatorname{MC}_{i}\left(p_{G i}\right)=\mathrm{a}_{i}+2 \mathrm{~b}_{i} p_{G i} \quad(\$ / M W h)
$$

At the beginning of any planning period, a GenCo's avoidable costs consist of the operational costs that it can avoid by shutting down production together with the portion of its fixed (non-operational) costs that it can avoid by taking appropriate additional actions such as asset re-use or re-sale. In order for production to proceed, revenues from production should at least cover avoidable costs. In the present study the GenCos do not incur start-up/shut-down or no-load costs, and all of their fixed costs are assumed to be sunk, i.e., non-avoidable. Consequently, the avoidable cost function $\mathrm{C}_{i}^{a}\left(\mathrm{p}_{G i}\right)$ for each

\footnotetext{
${ }^{12}$ At the other extreme, a dynamic-price contract with $\pi=$ $L M P_{k(j)}(H, D)$ would award all of the net surplus to the retail customers.
} 
GenCo $i$ for any hour $\mathrm{H}$ is given by the integral of its true hourly marginal cost function:

$$
\mathrm{C}_{i}^{a}\left(p_{G i}\right)=\int_{0}^{p_{G i}} \operatorname{MC}_{i}(p) d p=a_{i} p_{G i}+b_{i}\left[p_{G i}\right]^{2} \quad(\$ / h)
$$

where $\mathrm{p}_{G i}$ satisfies (7).

Suppose GenCo $i$, located at bus $k(i)$, is dispatched at level $\mathrm{p}_{G i}(\mathrm{H}, \mathrm{D})$ at price $\mathrm{LMP}_{k(i)}(\mathrm{H}, \mathrm{D})$ for hour $\mathrm{H}$ of the day-ahead market for day $\mathrm{D}+1$. The revenues due to GenCo $i$ for all 24 hours of day D+1, settled at the end of day D, are

$$
\operatorname{Rev}_{i}(D)=\sum_{H=00}^{23} L M P_{k(i)}(H, D) \cdot p_{G i}(H, D)
$$

Net earnings are defined as revenues minus avoidable costs. Let the avoidable costs incurred by GenCo $i$ on day D for any hour $\mathrm{H}$ of day $\mathrm{D}+1$ based on its day-D dispatch $\mathrm{p}_{G i}(\mathrm{H}, \mathrm{D})$ be denoted by $\mathrm{C}_{i}^{a}(\mathrm{H}, \mathrm{D})$. Then the net earnings of GenCo $i$ for all 24 hours of day $\mathrm{D}+1$, realized on day $\mathrm{D}$, are

$$
\mathrm{NE}_{i}(D)=\operatorname{Rev}_{i}(D)-\sum_{H=00}^{23} \mathrm{C}_{i}^{a}(H, D)
$$

Using standard market efficiency analysis [3], the GenCo net surplus realized on day $\mathrm{D}$ is then

$$
\operatorname{GenNetSur}(D)=\sum_{i=1}^{I} \mathrm{NE}_{i}(D)
$$

The ISO net surplus realized on day $\mathrm{D}$ is the difference between LSE payments and GenCo revenues for the day-ahead market for day D+1 that are settled at the end of day D. More precisely,

$$
\operatorname{ISONetSur}(D)=\sum_{j=1}^{J} \operatorname{Pay}_{j}(D)-\sum_{i=1}^{I} \operatorname{Rev}_{i}(D)
$$

Figure 2 provides a simple example of ISO net surplus collection for a 2-bus system during a particular hour $\mathrm{H}$. The LSE at bus 2 pays $\mathrm{LMP}_{2}$ to the ISO for each MW of its cleared fixed demand $\mathrm{p}_{L}^{F}$. A portion $\mathrm{M}$ of this demand is supplied by GenCo $\mathrm{G} 1$ at bus 1 , who receives $\mathrm{LMP}_{1}$ per MW from the ISO. The remaining portion $\left[\mathrm{p}_{L}^{F}-\mathrm{M}\right]$ of this demand is supplied by GenCo G2 at bus 2, who receives $\mathrm{LMP}_{2}>\mathrm{LMP}_{1}$ per MW from the ISO. The ISO net surplus for hour $\mathrm{H}$ is then calculated to be $\mathrm{M} \times\left[\mathrm{LMP}_{2}-\mathrm{LMP}_{1}\right]$.

Figure 2 illustrates several important general properties of ISO net surplus under LMP. As established in [8, Prop. 2.1], the ISO net surplus generated in any hour under a standard DC-OPF formulation, such as used in this study, is guaranteed to be nonnegative. On the other hand, congestion arising anywhere on a transmission grid necessarily results in the separation of LMPs at two or more bus locations [27]. Moreover, the day-ahead energy purchases of each LSE and the dayahead energy sales of each GenCo are settled each hour in accordance with the LMP determined at its own particular bus location. Consequently, under congested grid conditions, ISO net surplus will typically be strictly positive. ${ }^{13}$ These

\footnotetext{
${ }^{13}$ The qualifier "typically" is needed because, in special circumstances, a shadow price can vanish even though its corresponding inequality constraint holds with equality; the standard KKT-conditions do not rule this out. See footnote 16 for the relevance of this observation to ISO net surplus calculation.
}

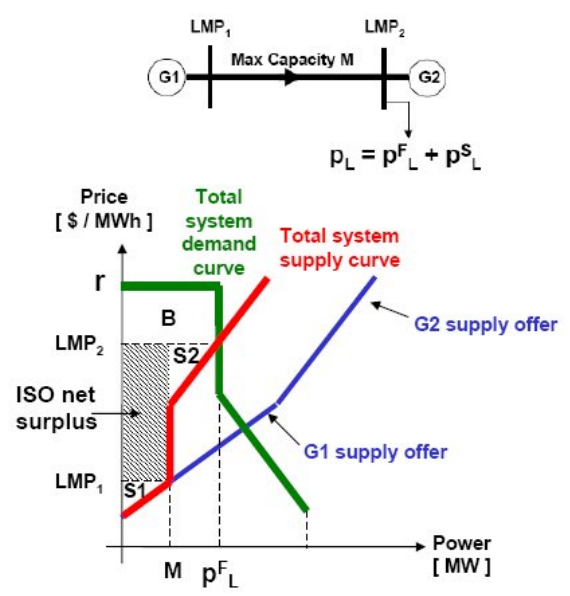

Fig. 2. Illustration of ISO net surplus collection for a simple 2-bus system with a branch limit $\mathrm{M}$ restricting power flow from the cheaper GenCo G1 at bus 1 to the load at bus 2. (Figure adapted from [26])

general ISO net surplus properties will be experimentally demonstrated below in Section IV.

The total net surplus $T N S(D)$ realized on day $\mathrm{D}$ is given by the sum of component net surpluses as follows:

$$
\operatorname{LSENetSur}(D)+\operatorname{GenNetSur}(D)+\operatorname{ISONetSur}(D)
$$

For example, TNS in Fig. 2 is the sum of the LSE net surplus B, the GenCo G1 net surplus S1, the GenCo G2 net surplus $\mathrm{S} 2$, and the ISO net surplus.

Finally, market efficiency is said to hold for day D if energy has been dispatched during day $\mathrm{D}$ in such a way that the maximum feasible amount of total net surplus TNS(D) defined in (14) has been extracted, conditional on existing physical conditions. For present purposes, these existing physical conditions include branch reactances, branch flow limits, LSE fixed demands, LSE reservation values, GenCo reservation values (true marginal cost functions), and true GenCo operating capacity limits.

\section{EXPERIMENTAL DESIGN}

\section{A. Overview}

This section sets out our experimental design. As will be seen, this design permits the systematic examination of the effects of two treatment factors - LSE demand-bid price sensitivity and GenCo learning - on ISO net surplus, market efficiency, and other related market outcomes.

We start with benchmark 5-bus and 30-bus test cases with no LSE price-sensitive demand and no GenCo learning. Some congestion arises in each of these benchmark cases, resulting in LMP separation and a positive ISO net surplus. We then carefully examine how ISO net surplus, market efficiency, and other related market outcomes are affected as we incrementally increase the amount of LSE demand-bid price sensitivity from $0 \%$ to $100 \%$ and as we endow the GenCos with learning capabilities enabling them to strategically report their supply offers for the day-ahead energy market. These incremental changes in the two treatment factors affect congestion on the grid, hence LMP separation and ISO net surplus, as well as 
many other market outcomes. However, comparisons back to the benchmark cases permit us to fully attribute all of these changes in market outcomes to specific changes in the two treatment factors.

For learning treatments, sequential hourly decisions by the LSEs, GenCos, and ISO are simulated for multiple 24hour days to permit us to examine the effects of GenCo learning over time on market outcomes. To control for random effects, we use thirty pseudo-random number seed values to initialize thirty distinct runs, each 1000 (5-bus) or 500 (30bus) simulated days in length. We also calibrate each GenCo's learning parameter settings to its particular attributes. For example, each GenCo $i$ 's "initial propensity" $q_{i}(1)$, reflecting its initial daily net earnings aspirations, is set in proportion to its maximum possible daily net earnings as determined from its action domain $\mathrm{AD}_{i}{ }^{14}$

Also, for simplicity, the regulated price $r(\$ / \mathrm{MWh})$ received by each LSE for the resale of its fixed demand to its retail customers under fixed-price contracts in the 5-bus and 30-bus test case experiments is set at a high-enough level that it has no effect on any experimental outcomes. This is the case for any value of $r$ that strictly exceeds all experimentally determined LMP levels calculated without imposing any upper bound on the LSEs' willingness to pay for their fixed demands.

The AMES(V2.05) download [19] includes complete input data files for all of the 5-bus and 30-bus test case experiments reported in this study, including the 30 pseudo-random number seed values, the action domain construction parameter values, and the learning parameter values used for learning treatments.

\section{B. Benchmark Test Cases}

Our benchmark 5-bus test case has the following structural, institutional, and behavioral features.

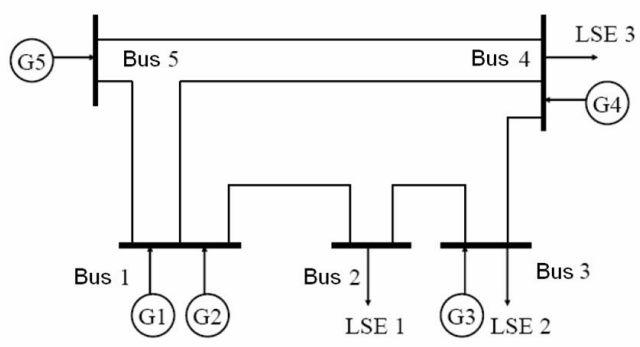

Fig. 3. Transmission grid for the benchmark 5-bus test case.

The wholesale power market operates over a 5-bus transmission grid as depicted in Fig. 3, with branch reactances, locations of LSEs and GenCos, and initial hour-0 LSE fixed demands adopted from a 5-bus test case [29] commonly used in ISO training manuals. True GenCo cost and capacity

\footnotetext{
${ }^{14}$ As explained in Section II-B and Appendix B, each GenCo $i$ 's action domain consists of finitely many marginal cost functions, each defined over a compact operating capacity interval. This imposes an intrinsic upper bound on attainable GenCo daily net earnings. The importance of calibrating learning algorithms to learning environments is highlighted by the "heat map" portrayals of GenCo net earnings outcomes under alternative learning parameter configurations provided in [28, Section V].
}

attributes are as depicted in Fig. 4. GenCos range from GenCo 5 , a relatively large coal-fired baseload unit with low marginal operating costs, to GenCo 4, a relatively small gas-fired peaking unit with relatively high marginal operating costs.

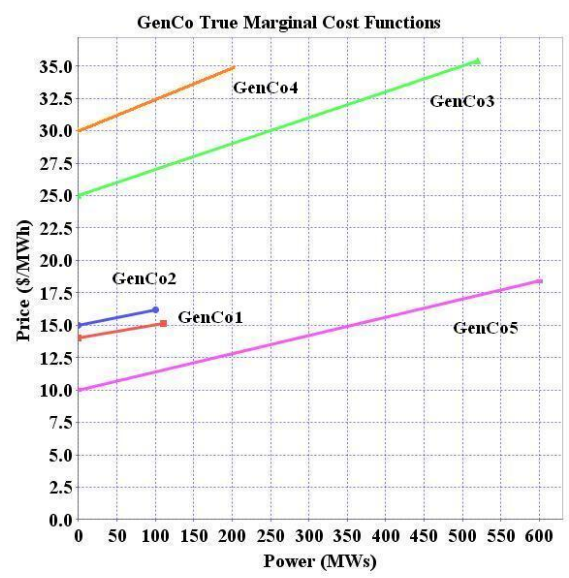

Fig. 4. GenCo true marginal cost functions and true capacity attributes for the benchmark 5-bus test case.

LSE demand in this benchmark case is $100 \%$ fixed (no price sensitivity). The LSE daily fixed-demand profiles are adopted from a case study presented in Shahidehpour et al. [30, p. 296297]. Hourly fixed demand varies from light (hour 4:00) to peak (hour 17:00). Finally, GenCos in this benchmark case are non-learners, meaning they report supply offers to the ISO for the day-ahead energy market that convey their true marginal cost functions and true operating capacity limits.

Complete input data for our benchmark 5-bus test case are provided in the input data file for the 5-bus test case included in the data directory of the AMES(V2.05) download [19].

Our benchmark 30-bus test case is based on the IEEE 30bus test case presented in Shahidehpour et al. [30, App. D.4, 477-478] with 9 GenCos, 21 LSEs, and 41 transmission grid branches. As in the benchmark 5-bus test case, LSE demand bids do not exhibit price sensitivity and the GenCos are nonlearners that report their true cost and capacity attributes to the ISO for the day-ahead energy market. Complete input data for our benchmark 30-bus test case are provided in the input data file for the 30-bus test case included in the data directory of the AMES(V2.05) download [19].

\section{R Measure for Demand-Bid Price Sensitivity}

The price-elasticity of demand (i.e., the percentage change in quantity demanded in response to a percentage change in price) varies all along the plot of any linear price-sensitive demand function such as (1). Hence, price-elasticity cannot be used to parameterize sensitivity to price in the present context. $^{15}$

\footnotetext{
${ }^{15}$ This is also true for real-world LSE demand bids. For example, in MISO [22, Section 5] an LSE's price-sensitive demand bid for each hour $\mathrm{H}$ of the day-ahead energy market must be submitted as a step function comprising no more than nine price-quantity blocks. The LSE's fixed demand must be separately submitted as a quantity-only block.
} 
To investigate the effects of changes in LSE demand-bid price sensitivity both with and without GenCo learning, we first defined the ratio

$$
R_{j}(H, D)=\frac{\operatorname{SLMax}_{j}(H, D)}{\left[p_{L j}^{F}(H, D)+\operatorname{SLMax}(H, D)\right]}
$$

The numerator of (15) denotes LSE $j$ 's maximum potential price-sensitive demand $\operatorname{SLMax}_{j}(\mathrm{H}, \mathrm{D})$ for hour $\mathrm{H}$ of the dayahead market in day D+1; cf. (2). The denominator of (15) denotes LSE $j$ 's maximum potential total demand for hour $\mathrm{H}$ of the day-ahead market in day D+1, i.e., the sum of its fixed demand and maximum potential price-sensitive demand.

We next set all of the LSE fixed demands $\mathrm{p}_{L j}^{F}(\mathrm{H}, \mathrm{D})$ to their positive benchmark-case values $\mathrm{BP}_{L j}^{F}(\mathrm{H})$ (differing by hour but not by day) and all of the maximum potential price-sensitive demands $\operatorname{SLMax}_{j}(\mathrm{H}, \mathrm{D})$ to their benchmarkcase value 0 to achieve a common value $R=0.0$ for the $R$ ratio (15) across all LSEs $j$ for each $\mathrm{H}$ and $\mathrm{D}$. We then systematically varied the settings for $\mathrm{p}_{L j}^{F}(\mathrm{H}, \mathrm{D})$ from their positive benchmark-case values $\mathrm{BP}_{L j}^{F}(\mathrm{H})$ to 0 and the settings for $\operatorname{SLMax}_{j}(\mathrm{H}, \mathrm{D})$ from 0 to the positive benchmark-case values $\mathrm{BP}_{L j}^{F}(\mathrm{H})$ for fixed demand so that a sequence of common $\mathrm{R}$ values was achieved for the LSEs ranging from $\mathrm{R}=0.0$ (100\% fixed demand) to $\mathrm{R}=1.0$ (100\% price-sensitive demand).

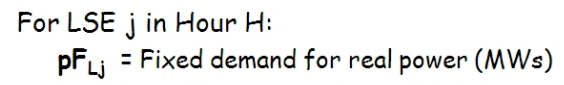

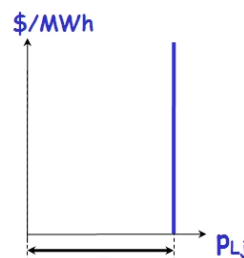

$P_{L j}^{F_{L}}$

(1) $R=0.0$

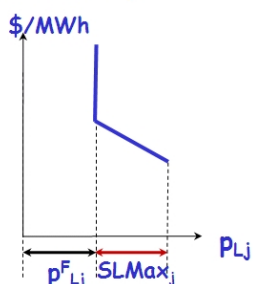

(2) $R=0.5$

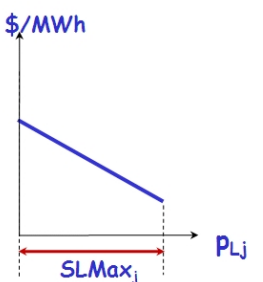

(3) $R=1.0$
(100\% Fixed Demand)

(100\% Price-Sensitive Demand)

Fig. 5. Illustration of the $\mathrm{R}$ ratio construction for the experimental control of relative LSE demand-bid price sensitivity in each hour $\mathrm{H}$.

Figure 5 illustrates the construction of $\mathrm{R}$ for the special cases $R=0.0, R=0.5$, and $R=1.0$. Note that a positive $R$ value indicates the LSEs are able to exercise at least some degree of resistance to higher prices through reductions in their quantity demands.

To prevent confounding effects arising from changes in the ordinate and slope values of the LSE price-sensitive demand bids in (1), these ordinate and slope values were held fixed across all experiments. The specific settings for these fixed ordinate and slope values (along with all benchmark-case values $\mathrm{BP}_{L j}^{F}(\mathrm{H})$ for LSE fixed demands) are provided in the input data files for the 5-bus and 30-bus test cases included with the AMES(V2.05) download [19].

\section{Key Findings}

\section{A. 5-Bus Benchmark-Case Findings}

During a typical day D for the benchmark 5-bus test case, the branch 1-2 connecting bus 1 to bus 2 is persistently congested. As a result, in each hour there is complete LMP separation across the grid.

TABLE I

HOURLY GENCO NET EARNINGS DURING A TYPICAL 24-HOUR DAY D FOR THE BENCHMARK 5-BUS TEST CASE.

\begin{tabular}{||c|rrrrr||}
\hline Hour & GenCo 1 & GenCo 2 & GenCo 3 & GenCo 4 & GenCo 5 \\
\hline \hline 00 & 67.81 & 1.15 & $1,105.79$ & 0.00 & $1,377.42$ \\
01 & 67.24 & 1.08 & 725.83 & 0.00 & $1,340.07$ \\
02 & 66.87 & 1.04 & 518.48 & 0.00 & $1,315.68$ \\
03 & 66.68 & 1.02 & 427.08 & 0.00 & $1,303.45$ \\
04 & 66.49 & 0.99 & 345.93 & 0.00 & $1,291.50$ \\
05 & 66.59 & 1.01 & 385.44 & 0.00 & $1,297.48$ \\
06 & 66.68 & 1.02 & 427.08 & 0.00 & $1,303.45$ \\
07 & 67.06 & 1.06 & 61874 & 0.00 & $1,327.95$ \\
08 & 68.00 & 1.18 & $1,247.51$ & 0.00 & $1,389.76$ \\
09 & 68.75 & 1.28 & $1,909.70$ & 0.00 & $1,440.36$ \\
10 & 68.94 & 1.30 & $2,097.94$ & 0.00 & $1,453.20$ \\
11 & 69.03 & 1.31 & $2,193.68$ & 0.00 & $1,459.54$ \\
12 & 68.94 & 1.30 & $2,097.94$ & 0.00 & $1,453.20$ \\
13 & 68.75 & 1.28 & $1,909.70$ & 0.00 & $1,440.36$ \\
14 & 68.66 & 1.26 & $1,820.44$ & 0.00 & $1,434.06$ \\
15 & 68.66 & 1.26 & $1,820.44$ & 0.00 & $1,434.06$ \\
16 & 69.03 & 1.31 & $2,193.68$ & 0.00 & $1,459.54$ \\
17 & 0.02 & 0.00 & $18,654.46$ & 142.27 & $1,912.03$ \\
18 & 57.62 & 0.22 & $4,980.40$ & 0.00 & $1,573.60$ \\
19 & 69.41 & 1.37 & $2,601.82$ & 0.00 & $1,485.24$ \\
20 & 69.31 & 1.35 & $2,497.56$ & 0.00 & $1,478.84$ \\
21 & 69.13 & 1.33 & $2,291.68$ & 0.00 & $1,465.89$ \\
22 & 68.66 & 1.26 & $1,820.44$ & 0.00 & $1,434.06$ \\
23 & 68.09 & 1.19 & $1,324.32$ & 0.00 & $1,396.18$ \\
\hline Total & $1,556.41$ & 26.58 & $56,016.09$ & 142.27 & $34,266.94$ \\
\hline
\end{tabular}

As depicted in Table I, GenCos 1 and 2 have relatively low net earnings in all hours and particularly in the peak-demand hour 17. This occurs for two reasons. First, as depicted in Fig. 3, these two GenCos are located at bus 1, hence they are semi-islanded away from the "load pocket" at buses 2 through 4 due to the persistent congestion on branch 1-2. Second, as seen in Fig. 4, these two GenCos have relatively small operating capacities.

In contrast, GenCo 3 located at the load-pocket bus 3 has relatively high net earnings in every hour, particularly in the peak-demand hour 17. This occurs because GenCo 3 is a pivotal supplier in most hours, meaning its relatively large capacity is needed to meet fixed demand. Moreover, during hour 17 , GenCo 3 is dispatched at its maximum capacity and GenCo 5 is semi-islanded from bus 3 due to the congestion on branch 1-2. Consequently, to meet demand at bus 3 during hour 17, the ISO needs to call upon the expensive peaking unit, GenCo 4 . This substantially spikes the LMP at bus 3 in hour 17, and hence the net earnings of GenCo 3.

GenCo 5 is a base-load generator with large capacity and low marginal cost that is never dispatched at its maximum capacity. Consequently, although it is a pivotal supplier, its net earnings remain relatively flat.

Fig. 6 presents benchmark-case hourly financial flows during a typical day D. Note that LSE payments are persistently higher than GenCo revenues, particularly during the peakdemand hour 17. Consequently, ISO net surplus is persistently positive with a spike during hour 17.

Indeed, for a typical day $\mathrm{D}$ for the benchmark case $(\mathrm{R}=0.0)$, LSE payments are $\$ 754,919.61$ and GenCo revenues are 


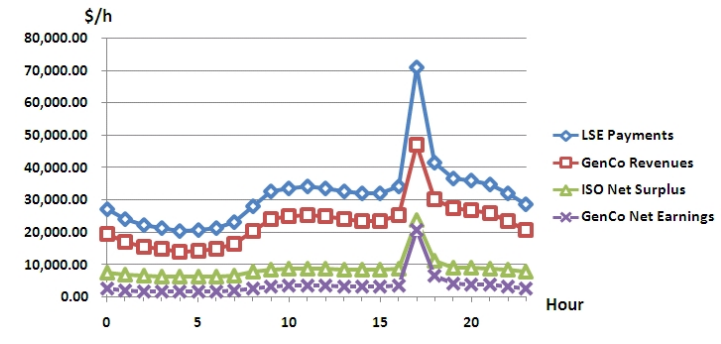

Fig. 6. LSE payments, GenCo revenues, ISO net surplus, and GenCo net earnings during a typical 24-hour day D for the benchmark 5-bus test case.

$\$ 545,508.54$. Consequently, ISO net surplus is $\$ 209,411.07$, which is about 2.3 times the amount $\$ 92,008.30$ of GenCo net earnings.

\section{B. 5-Bus Net Surplus Distribution Findings with Learning and Price-Sensitive Demand}

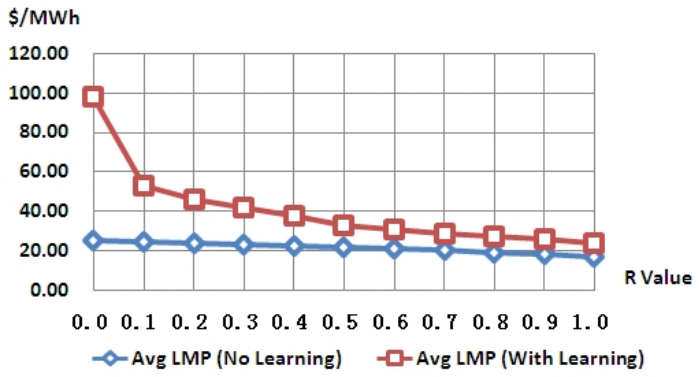

Fig. 7. Mean outcomes for average hourly LMP values on day 1000 for the benchmark 5-bus test case extended to include GenCo learning and LSE demand varying from $\mathrm{R}=0.0$ ( $100 \%$ fixed) to $\mathrm{R}=1.0$ ( $100 \%$ price sensitive).

For each R treatment, both with and without GenCo learning, congestion persistently occurs on branch $1-2$. As seen in Fig. 7, the extension of the benchmark 5-bus test case to include GenCo learning and price-sensitive demand results in a substantial increase in mean LMP outcomes, particularly for small values of R. This substantial LMP increase arises because each GenCo $i$ learns over time to exercise economic capacity withholding, i.e., to submit to the ISO reported marginal cost functions (6) that lie strictly above its true marginal cost function (8).

This economic capacity withholding by the learning GenCos also has dramatic effects on ISO net surplus collection. These dramatic effects are graphically depicted in Figs. 8 and 9 and numerically reported in Tables II and III.

Specifically, Fig. 8 and Table II present financial flows on a typical day $\mathrm{D}$ for the benchmark 5-bus test case extended to permit demand to vary from $\mathrm{R}=0.0$ ( $100 \%$ fixed) to $\mathrm{R}=1.0$ (100\% price sensitive). As in the benchmark case, the GenCos submit supply offers to the ISO that reflect their true cost and capacity attributes. In contrast, Fig. 9 and Table III present corresponding financial flows on day 1000 for the case in which all five GenCos have learning capabilities enabling them to engage in economic capacity withholding. In particular, each GenCo applies learning to its past net earnings outcomes in an attempt to determine which marginal cost function it should report to the ISO to achieve its highest possible daily net earnings.

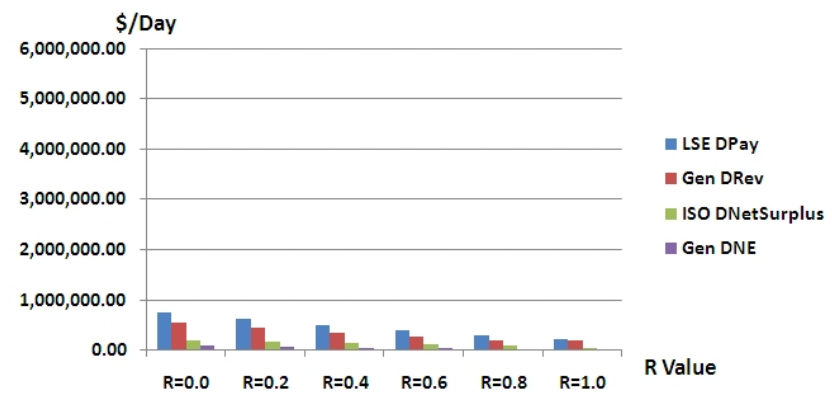

Fig. 8. LSE payments, GenCo revenues, ISO net surplus, and GenCo net earnings (i.e., net surplus) during a typical day $\mathrm{D}$ for the benchmark 5-bus test case extended to permit LSE demand to vary from $\mathrm{R}=0.0$ (100\% fixed) to $\mathrm{R}=1.0$ ( $100 \%$ price sensitive)

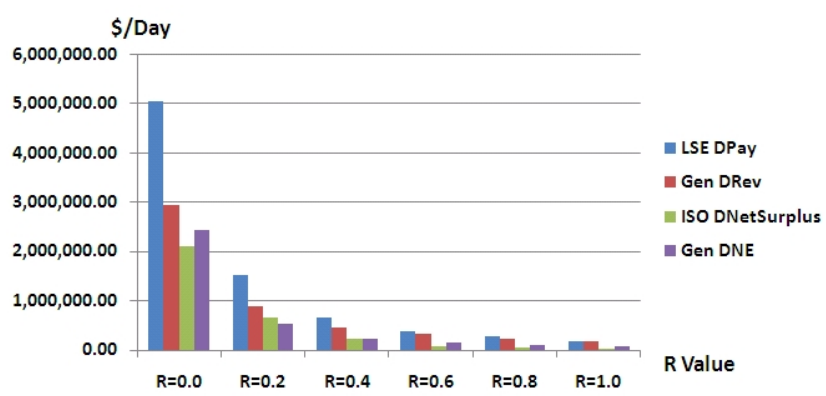

Fig. 9. Mean outcomes for LSE payments, GenCo revenues, ISO net surplus, and GenCo net earnings (i.e., net surplus) during day 1000 for the benchmark 5-bus test case extended to include GenCo learning and LSE demand varying from $\mathrm{R}=0.0$ ( $100 \%$ fixed) to $\mathrm{R}=1.0$ ( $100 \%$ price sensitive)

Consider, for example, the $\mathrm{R}=0.0$ ( $100 \%$ fixed demand) daily data presented for the benchmark no-learning case in Fig. 8 and Table II and for the learning case in Fig. 9 and Table III. Mean LSE payments on day 1000 for the learning case are $\$ 5,040,530.89$, an approximately 6.7 -fold increase relative to the benchmark no-learning case. Note, however, that mean ISO net surplus on day 1000 for the learning case is then $\$ 2,097,620.96$, an almost ten-fold increase relative to the benchmark no-learning case. Indeed, ISO net surplus under learning is similar in magnitude to GenCo net surplus under learning $(\$ 2,441.646 .71)$.

Since total demand for $\mathrm{R}=0.0$ is the same under learning and no learning, the ten-fold increase in mean ISO net surplus under learning implies that the mean LMP paid by the LSEs is substantially higher than the mean LMP received by the GenCos. This is due to the approximately six-fold increase under learning in the mean LMP for bus 2, which has the largest load (LSE 1) and no generation, and to the much smaller increases under learning in the mean LMPs for buses 1 and 5, which have generation but no load.

Another regularity observed in Figs. 8 and 9, as well as in Tables II and III, is that GenCo net surplus, LSE payments, and ISO net surplus each exhibit a marked monotonic decrease as $\mathrm{R}$ increases from $\mathrm{R}=0.0$ (100\% fixed demand) to $\mathrm{R}=1.0(100 \%$ 
TABLE II

GENCO NET SURPLUS, LSE PAYMENTS, AND ISO NET SURPLUS ON A TYPICAL DAY D FOR THE BENCHMARK 5-BUS TEST CASE EXTENDED TO PERMIT LSE DEMAND TO VARY FROM $R=0.0$ ( $100 \%$ FIXED) TO $R=1.0$ (100\% PRICE SENSITIVE).

\begin{tabular}{||c||r|r|r|r|r|r||}
\hline & $\mathrm{R}=0.0$ & $\mathrm{R}=0.2$ & $\mathrm{R}=0.4$ & $\mathrm{R}=0.6$ & $\mathrm{R}=0.8$ & $\mathrm{R}=1.0$ \\
\hline \hline Gen1NetEarn(D) & $1,556.41$ & $1,412.41$ & $1,316.90$ & $1,239.14$ & $1,193.74$ & $1,145.06$ \\
Gen2NetEarn(D) & 26.58 & 10.93 & 4.30 & 1.42 & 1.21 & 0.43 \\
Gen3NetEarn(D) & $56,016.09$ & $35,651.85$ & $21,354.23$ & $11,479.86$ & $2,874.96$ & $2,493.13$ \\
Gen4NetEarn(D) & 142.27 & 13.91 & 0.00 & 0.00 & 0.00 & 0.00 \\
Gen5NetEarn(D) & $34,266.94$ & $32,253.34$ & $30,460.22$ & $28,531.08$ & $26,246.37$ & $23,364.36$ \\
\hline GenNetSur(D) & $92,008.30$ & $69,342.45$ & $53,135.65$ & $41,251.49$ & $30,316.28$ & $27,002.99$ \\
\hline TotLSEPay(D) & $754,919.61$ & $625,704.76$ & $506,698.47$ & $399,806.50$ & $301,537.97$ & $231,945.71$ \\
\hline ISONetSur(D) & $209,411.07$ & $184,253.35$ & $159,977.47$ & $131,939.70$ & $93,483.24$ & $43,003.42$ \\
\hline \hline
\end{tabular}

TABLE III

MEAN OUTCOMES (WITH STANDARD DEVIATIONS) FOR GENCO NET SURPLUS, LSE PAYMENTS, AND ISO NET SURPLUS ON DAY 1000 FOR THE BENCHMARK 5-BUS TEST CASE EXTENDED TO INCLUDE GENCO LEARNING AND LSE DEMAND VARYING FROM R=0.0 (100\% FIXED) TO R=1.0 (100\% PRICE SENSITIVE).

\begin{tabular}{|c|c|c|c|c|c|c|}
\hline & $\mathrm{R}=0.0$ & $\mathrm{R}=0.2$ & $\mathrm{R}=0.4$ & $\mathrm{R}=0.6$ & $\mathrm{R}=0.8$ & $\mathrm{R}=1.0$ \\
\hline$\overline{\text { Gen1NetEarn(1000) }}$ & $\begin{array}{r}69,219.61 \\
(64,055.42)\end{array}$ & $\begin{array}{r}21,950.82 \\
(32,888.20)\end{array}$ & $\begin{array}{r}18,028.37 \\
(20,401.49)\end{array}$ & $\begin{array}{r}15,317.64 \\
(17,342.48)\end{array}$ & $\begin{array}{r}11,460.38 \\
(13,341.31)\end{array}$ & $\begin{array}{r}6,075.72 \\
(8,585.60)\end{array}$ \\
\hline$\overline{\text { Gen2NetEarn(1000) }}$ & $\begin{array}{r}54,548.72 \\
(57,868.92)\end{array}$ & $\begin{array}{r}18,919.31 \\
(30,102.78)\end{array}$ & $\begin{array}{r}13,271.49 \\
(19,648.72)\end{array}$ & $\begin{array}{r}11,141.69 \\
(15,916.37)\end{array}$ & $\begin{array}{r}8,368.95 \\
(13,528.49)\end{array}$ & $\begin{array}{r}5,061.87 \\
(9,487.15)\end{array}$ \\
\hline$\overline{\text { Gen3NetEarn(1000) }}$ & $\begin{array}{l}1,725,216.72 \\
(389,906.14)\end{array}$ & $\begin{array}{r}293,743.16 \\
(269,901.79)\end{array}$ & $\begin{array}{r}41,122.50 \\
(20,776.25)\end{array}$ & $\begin{array}{r}8,213.84 \\
(7,847.69)\end{array}$ & $\begin{array}{r}4,059.61 \\
(3,343.84)\end{array}$ & $\begin{array}{r}2,316.01 \\
(1,775.20)\end{array}$ \\
\hline$\overline{\text { Gen4NetEarn(1000) }}$ & $\begin{array}{r}321,907.08 \\
(153,782.17)\end{array}$ & $\begin{array}{r}38,678.95 \\
(73,333.88)\end{array}$ & $\begin{array}{r}5,589.68 \\
(14,969.93)\end{array}$ & $\begin{array}{r}66.32 \\
(161.70)\end{array}$ & $\begin{array}{r}14.11 \\
(51.51)\end{array}$ & $\begin{array}{r}3.38 \\
(18.22)\end{array}$ \\
\hline$\overline{\text { Gen5NetEarn(1000) }}$ & $\begin{array}{r}270,754.58 \\
(124,835.20)\end{array}$ & $\begin{array}{r}167,938.19 \\
(113,128.59)\end{array}$ & $\begin{array}{r}149,920.04 \\
(85,701.22)\end{array}$ & $\begin{array}{r}118,535.14 \\
(50,853.37)\end{array}$ & $\begin{array}{r}83,774.92 \\
(32,392.38)\end{array}$ & $\begin{array}{r}54,920.77 \\
(20,700.86)\end{array}$ \\
\hline$\overline{\text { GenNetSur(1000) }}$ & $\begin{array}{l}2,441,646.71 \\
(153,782.17)\end{array}$ & $\begin{array}{r}541,230.41 \\
(73,333.88)\end{array}$ & $\begin{array}{l}227,932.07 \\
(14,969.93)\end{array}$ & $\begin{array}{r}153,274.62 \\
(161.70)\end{array}$ & $\begin{array}{r}107,677.99 \\
(51.51)\end{array}$ & $\begin{array}{r}68,377.76 \\
(18.22)\end{array}$ \\
\hline$\overline{\text { TotLSEPay(1000) }}$ & $\begin{array}{r}5,040,530.89 \\
(1,043,543.03)\end{array}$ & $\begin{array}{l}1,526,994.60 \\
(975,375.28)\end{array}$ & $\begin{array}{r}663,801.01 \\
(209,686.70) \\
\end{array}$ & $\begin{array}{l}377,524.06 \\
(11,366.32)\end{array}$ & $\begin{array}{l}271,061.40 \\
(26,241.77)\end{array}$ & $\begin{array}{r}183,118.99 \\
(33,324.23)\end{array}$ \\
\hline$\overline{\text { ISONetSur(1000) }}$ & $\begin{array}{l}2,097,620.96 \\
(632,303.71)\end{array}$ & $\begin{array}{r}647,130.97 \\
(633,129.12)\end{array}$ & $\begin{array}{r}206,219.65 \\
(197,896.93)\end{array}$ & $\begin{array}{r}57,450.22 \\
(48,696.64)\end{array}$ & $\begin{array}{r}31,680.94 \\
(30,789.07)\end{array}$ & $\begin{array}{r}14,879.79 \\
(11,016.23)\end{array}$ \\
\hline
\end{tabular}

price-sensitive demand). The explanation for this monotonic decrease is as follows.

Consider, first, the benchmark no-learning case in Table II. Given low R values, the LSEs have very low price resistance; their fixed demands constitute the bulk of their total demands. Around the peak-demand hour 17, due in part to congestion on branch 1-2, the ISO must dispatch the most expensive GenCos 3, 4, and 5 to meet the large LSE fixed demand, i.e., these GenCos are pivotal suppliers for hour 17. This results in relatively high LMPs.

As $\mathrm{R}$ increases, however, the LSEs are increasingly able to resist high prices through demand withholding. This results in lower LMPs, lower total demand, and lower avoidable costs of production. GenCo revenues and LSE payments are thus lower, and GenCo net earnings are also lower because the decrease in GenCo avoidable costs is more than offset by the decrease in GenCo revenues. Similarly, ISO net surplus is lower because the decrease in GenCo revenues is more than offset by the decrease in LSE payments.

Next consider the day-1000 data for the learning case in Table III. For $\mathrm{R}=0.0$ the mean outcomes for GenCo net surplus, LSE payments, and ISO net surplus under learning are substantially greater than their corresponding values under no learning reported in Table II. As R increases, however, the mean outcomes for LSE payments and ISO net surplus under learning both eventually drop below their corresponding values under no learning, the switch point occurring at $\mathrm{R}=0.6$.

The explanation for these switch points can be deduced from detailed LMP and total demand findings for the nolearning and learning cases. When GenCos are learners, low $\mathrm{R}$ values (implying large fixed demands) provide pivotal suppliers with a substantial opportunity to engage in profitable economic capacity withholding. This dramatically increases LMPs relative to the no-learning case, particularly at the loadonly bus 2 . Since total demand for the learning case is only modestly lower than for the no-learning case for low $\mathrm{R}$ values, the end result is substantially greater GenCo revenues, LSE payments, and ISO net surplus.

On the other hand, as R increases and the LSEs acquire an increasing ability to resist high prices through demand withdrawal, the learning GenCos are increasingly forced to compete with each other for dispatch by lowering their reported marginal costs. This competitive process results in lower LMPs. However, the LMPs resulting under learning remain higher than under no learning for all $\mathrm{R}$ values, which in turn induces the LSEs to engage in greater demand withholding under learning.

The end result is that mean GenCo revenues, mean LSE payments, and mean ISO net surplus under learning all fall below their corresponding no-learning values as $\mathrm{R}$ approaches 1.0 due to the relatively strong contraction in total demand under learning. As can be verified from the GenCo net earnings 
TABLE IV

COMPARISON OF NET SURPLUS OUTCOMES ON DAY 1000 FOR THE 5-BUS TEST CASE WITHOUT LEARNING (BENCHMARK) VERSUS WITH GENCO LEARNING (MEANS AND STANDARD DEVIATIONS) AS LSE DEMAND VARIES FROM R=0.0 (100\% FIXED) TO R=1.0 (100\% PRICE SENSITIVE).

\begin{tabular}{|c|c|c|c|c|c|c|}
\hline & $\mathrm{R}=0.0$ & $\mathrm{R}=0.2$ & $\mathrm{R}=0.4$ & $\mathrm{R}=0.6$ & $\mathrm{R}=0.8$ & $\mathrm{R}=1.0$ \\
\hline "GenNetSur(1000) & $\overline{92,008.30}$ & $\overline{699,342.45}$ & $253,135.65$ & $\overline{441,251.49}$ & $30,316.28$ & $27,002.99$ \\
\hline LSENetSur(1000) & $6,118,410.39$ & $4,937,440.19$ & $3,739,406.53$ & $2,530,696.32$ & $1,317,250.86$ & $95,531.85$ \\
\hline ISONetSur(1000) & $209,411.07$ & $184,253.35$ & $159,977.47$ & $131,939.70$ & $93,483.24$ & $43,003.42$ \\
\hline TNS(1000) & $6,419,829.76$ & $5,191,035.99$ & $3,952,519.65$ & $2,703,887.51$ & $1,441,050.38$ & $165,538.26$ \\
\hline$\overline{\text { GenNetSur(1000) }}$ & $\begin{array}{l}2,441,646.71 \\
(153,782.17)\end{array}$ & $\begin{array}{l}541,230.41 \\
(73,333.88)\end{array}$ & $\begin{array}{l}227,932.07 \\
(14,969.93)\end{array}$ & $\begin{array}{r}153,274.62 \\
(161.70)\end{array}$ & $\begin{array}{r}107,677.99 \\
(51.51)\end{array}$ & $\begin{array}{r}68,377.76 \\
(18.22)\end{array}$ \\
\hline$\overline{\overline{\text { LSENetSur(1000) }}}$ & $\begin{array}{r}1,832,799.11 \\
(1,043,543.03)\end{array}$ & $\begin{array}{l}3,977,731.25 \\
(980,836.96)\end{array}$ & $\begin{array}{l}3,494,823.67 \\
(231,030.43)\end{array}$ & $\begin{array}{r}2,467,054.80 \\
(42,475.32)\end{array}$ & $\begin{array}{r}1,273,364.42 \\
(29,287.77)\end{array}$ & $\begin{array}{r}52,119.91 \\
(24,563.47)\end{array}$ \\
\hline$\overline{\text { ISONetSur(1000) }}$ & $\begin{array}{l}2,097,620.96 \\
(632,303.71)\end{array}$ & $\begin{array}{r}647,130.97 \\
(633,129.12)\end{array}$ & $\begin{array}{r}206,219.65 \\
(197,896.93)\end{array}$ & $\begin{array}{r}57,450.22 \\
(48,696.64)\end{array}$ & $\begin{array}{r}31,680.94 \\
(30,789.07)\end{array}$ & $\begin{array}{r}14,879.79 \\
(11,016.23)\end{array}$ \\
\hline$\overline{\mathrm{TNS}(1000)}$ & $6,372,006.78$ & $5,166,092.63$ & $3,928,975.39$ & $2,677,779.64$ & $1,412,723.35$ & $135,377.46$ \\
\hline$\overline{\text { TNSLoss(1000) }}$ & $47,762.98$ & $24,943.36$ & $23,544.27$ & $26,107.87$ & $28,327.03$ & $30,160.80$ \\
\hline
\end{tabular}

data provided in Table III, the most expensive GenCo 4 is at the greatest disadvantage in this competitive process while the least expensive GenCo 5 is most advantaged.

\section{5-Bus Total Net Surplus Size and Distribution Findings with Learning and Price-Sensitive Demand}

How are total net surplus (TNS) outcomes affected by LSE demand-bid price sensitivity and by GenCo learning? To answer this question, LSE net surplus needs to be calculated, which in turn requires a calculation of LSE benefits from retail sales as an offset to LSE payments for wholesale purchases.

Recall from Section II-B that each LSE extracts all net surplus from its retail customers under dynamic-price contracts. For concreteness, suppose the LSEs' regulated retail-resale price $r$ on its fixed-price contracts is set at $\$ 300 / \mathrm{MWh}$, a value that strictly exceeds all LMP outcomes determined for the 5bus test case in the absence of any upper bound on the LSEs' willingness to pay for fixed demands. This ensures that this setting of $r$ has no effect on our previously determined 5-bus dispatch or LMP solution outcomes.

Under these assumptions, TNS size and distribution outcomes on day 1000 are reported in Table IV. These outcomes show that, as the treatment changes from no learning to learning, and from larger to smaller $\mathrm{R}$ values (less price sensitivity of demand), there is an increasing redistribution of net surplus away from LSEs and towards GenCos and the ISO. This redistribution is particularly substantial for the learning treatment with $\mathrm{R}=0.0$ ( $100 \%$ fixed demand).

The final row of Table IV shows that, for each $\mathrm{R}$ value, the introduction of learning results in a loss of efficiency (reduction in TNS), particularly so for the case $\mathrm{R}=0.0$. The TNS loss at $R=0.0$ is entirely due to out-of-merit-order dispatch resulting from differential exercise of economic capacity withholding by differently situated learning GenCos. The TNS loss at positive $\mathrm{R}$ values is due in part to out-of-merit-order dispatch and in part to a reduction in cleared price-sensitive demand due to the higher LMPs resulting from economic capacity withholding.

\section{30-Bus ISO Net Surplus Findings}

Due to space limitations, we report only a sampling of results for the 30-bus test case with $\mathrm{R}=0.0$ (100\% fixed demand), both with and without GenCo learning.

As seen in Table V, for the no-learning case the typical ISO daily net surplus collection is $\$ 28,588$, and for the learning case the mean ISO net surplus collection on day 500 is $\$ 53,868.30$, nearly double the amount for the no-learning case. This increase in ISO net surplus under learning is qualitatively similar to the findings for the 5-bus test case. However, the size of this increase under learning (an approximate doubling) is not as large as for the 5-bus test case, a reflection of the increased rivalry among the more numerous GenCos in the 30-bus test case that results in a more difficult learning environment and less economic capacity withholding.

TABLE V

MEAN OUtCOMES (WITH STANDARD DEVIATIONS) FOR GENCO NET SURPLUS, TOTAL LSE PAYMENTS, AND ISO NET SURPLUS ON DAY 500 FOR THE BENCHMARK 30-BUS TEST CASE WITH R=0.0 (100\% FIXED DEMAND), BOTH WITH AND WITHOUT GENCO LEARNING.

\begin{tabular}{||c||r|r|}
\hline & No Learning & With Learning \\
\hline GenNetSur(500) & $14,210.01$ & $\begin{array}{r}142,866.39 \\
(67,530.19)\end{array}$ \\
\hline TotLSEPay(500) & $110,853.01$ & $285,531.70$ \\
& $28,588.00$ & $(74,214.33)$ \\
\hline ISONetSur(500) & $53,868.30$ \\
\hline \hline
\end{tabular}

\section{EMPIRICAL COMPARISONS}

This section compares the simulated ISO net surplus outcomes presented in Section IV with data on actual ISO net surplus outcomes as presented in the market reports [31]- [34] for PJM, MISO, ISO-NE, and CAISO.

The most complete reporting appears to be provided by PJM. In [31, Table 2-47, p. 48], the 2008 average cleared fixed plus price-sensitive demand in the PJM day-ahead market is given as $76,961 \mathrm{MWh}$ whereas the average cleared pricesensitive demand in the PJM day-ahead market is given as only 1,846 MWh. This implies an R-ratio equal to $\mathrm{R}=0.02$, which 
is close to $\mathrm{R}=0.0$ ( $100 \%$ fixed demand). In [31, Section 7 , pp. 342)] the total congestion cost is said to "represent the overall charge or credit to a zone," which we interpret to mean the difference between load payments to the ISO and generation credits (revenues) received from the ISO, i.e., ISO net surplus. On page 339 the 2008 day-ahead congestion costs for PJM are given as $\$ 2.66$ billion. This is approximately $7 \%$ of 2008 total PJM billings, listed as $\$ 34.3$ billion.

In comparison, consider the simulation outcomes reported in Table $\mathrm{V}$ for our 30-bus test case with $\mathrm{R}=0.0$. For the nolearning case, the ratio of ISO daily net surplus to total daily billings, measured as [GenCo daily revenues + LSE daily payments], is about $15 \%$. For the learning case, the ratio of ISO daily net surplus to total daily billings is about $10 \%$. The latter learning-case findings are in line with the $7 \%$ empirical findings for PJM, particularly since total PJM billings include settlements for black start, ancillary services, reactive services, Financial Transmission Right (FTR) payouts, Auction Revenue Right (ARR) credits, and transmission charges in addition to settlements for load and generation day-ahead trades.

In Fig. 46 (p. 68) of [32, Section V], the 2008 congestion cost for the MISO day-ahead market is listed as approximately $\$ 500$ million. For MISO, the congestion cost associated with any interface is defined (p. 93) as "the difference in LMP prices across the interface multiplied by the amount of the (power) transfer."

In [33, Section 3.4, p. 70], the combined 2008 Net Congestion Revenue for the ISO-NE real-time and day-ahead markets is listed as $\$ 121$ million. The net congestion revenue is calculated as the product of branch flows and branch shadow prices. ${ }^{16}$ In [34, Section 5, p. 5.3(103)], the CAISO interzonal congestion charges for the day-ahead and hour-ahead markets in year 2008 are listed as $\$ 176$ million. These charges are calculated as the product of branch shadow prices and the branch power flows on a subset of branches connecting variously specified zones rather than the difference between load payments and generator revenues across all buses (pricing locations), as used in this study.

According to the ISO market reports [31]- [34], the ISO net surplus collections for PJM, MISO, ISO-NE, and CAISO are largely allocated to FTR/CRR holders. For example, as reported in [31, p. 417], PJM allocates its total congestion costs as revenues to FTR holders, including GenCos, LSEs, and pure speculators with no physical generation or load obligations. Any extra amount remaining at the end of the year is allocated to LSEs as payment offsets in accordance with load-ratio shares. Similarly, as reported in [32, Section $\mathrm{V}]$, MISO distributes its congestion revenues as payments to FTR holders, including holders of special types of FTRs created to protect entities with pre-existing agreements to use the transmission system. Surpluses in one month are used to fund shortfalls in other months during each year, with FTR

\footnotetext{
${ }^{16}$ For a DC-OPF problem formulation (no losses), the ISO net surplus $(\$ / \mathrm{h})$ collected during any given hour can equivalently be expressed as the summation across all congested branches of the product of branch shadow prices ( $\$ / M W h)$ and branch power limits (MW). See, for example, [35, Section 3.2.4, Eqs(3.68-3.71)]. This equivalence does not hold for an AC-OPF problem formulation.
}

payments being reduced pro rata if a shortfall persists at the end of the year.

\section{CONCLUding REMARKS}

The basic responsibility undertaken by not-for-profit ISOs in day-ahead energy markets managed by LMP is to maximize total net surplus (TNS) subject to system reliability and feasibility constraints. An important issue highlighted in this study is whether this constrained maximization of TNS properly encourages efficient market operations. As seen in Section II-B, two concerns arise. First, the ISO must rely on reported rather than actual GenCo cost and capacity attributes when calculating TNS. Second, a net surplus dollar accruing to private traders is weighed equally with a net surplus dollar accruing to the ISO itself.

The simulation findings in Section IV show that ISO net surplus can be substantial when LSE demand is predominately fixed (insensitive to price) and GenCos can learn over time to strategically report supply offers with higher-thantrue marginal costs. In [36] the authors note that "under the current ISO practice, the (ISO net surplus) gathered by the ISO is largely returned to the load and transmission owners, resembling the government surplus as part of the social surplus in welfare economics." However, welfare economists do not assert the unqualified desirability of assigning government netsurplus dollars (e.g., tax revenues) the same weight as private trader net-surplus dollars in market objective functions, as is done in the ISO TNS objective function (14). An equal weighting would be especially problematic if the government were to redistribute its net-surplus dollars to third parties with high entry barriers and this redistribution effectively rewarded these third parties for maintaining social costs that the government hoped to alleviate.

A key issue for the ISO TNS objective function (14) is whether a dollar flowing to the ISO is properly treated as having the same social benefit as a dollar flowing to a private energy trader. The answer surely depends on social opportunity costs, i.e., on the net social benefits of alternative uses to which such dollars could be put.

As reported in Section V, the current practice in many U.S. wholesale power markets under LMP is to use ISO net surplus collections largely as revenue payments to FTR/CRR holders. This practice could lead to an overall increase in TNS over the longer run (i.e., to improved dynamic market efficiency) to the extent that it either directly or indirectly incentivizes socially beneficial transmission investments that alleviate congestion. However, such an outcome is doubtful.

First, the extent to which ISO net surplus payouts to FTR/CRR holders actually incentivize new transmission investment is unclear ( [10], [13, Section 4.2]). ${ }^{17}$ Second, transmission investment needs can arise for reasons other than congestion (e.g., the need to reach distributed energy resources), and congestion might better be alleviated by more

\footnotetext{
${ }^{17}$ For example, the CAISO report [10, p. ES-3] reaches the following conclusion: "...the reality has been that the LMP differences have not provided enough incentives to upgrade key facilities even after many types of FTRs and CRRs are provided."
} 
local generation rather than by more transmission capacity. Consequently, the ability of ISO net surplus collections to appropriately signal the need for new transmission is questionable in any case. Third, while the social benefits associated with ISO net surplus payouts to FTR/CRR holders are unclear, we do have some read on the sizeable nature of the social costs. Benjamin [37, Section V] empirically estimates that FTR market imperfections in ISO-NE, NYISO, and PJM from 2006 through 2008 resulted in hundreds of millions of dollars of additional annual expenses for retail rate-payers in these energy regions, and that this problem appears to be worsening over time.

In addition, as seen in Section $\mathrm{V}$, in some energy regions the ISO net surplus collections not needed for FTR/CRR payments during a year are used to offset LSE payments. Here, however, it is important to keep in mind the intended market efficiency rationale for LMP pricing in relation to demand: namely, to provide an incentive to LSEs to bid demand into the system when and where it can be serviced most cheaply. This incentivization could significantly gain in importance if retail markets heed growing pressures to introduce advanced metering and other technologies permitting retail consumers to better tailor their energy demands to wholesale energy prices and to choose their retail suppliers [15], [16]. To the extent that the allocation of ISO net surplus to LSEs as LMP payment offsets dampens their incentive to minimize these payments through appropriate retail customer contracting, it could become an increasing source of social inefficiency in future years.

Another issue also arises. As seen in Section IV, ISO and GenCo net surplus collections dramatically increase when the price-sensitivity of demand is low and learning GenCos exercise economic capacity withholding. On the other hand, LSE payments also dramatically increase. This would appear to provide a desirable incentive to pure LSEs (those without generation ownership) to support congestion reduction measures, increased price-sensitivity of demand, and increased oversight to curtail GenCo withholding. Currently, however, LSE payments for fixed demand at wholesale are typically recovered through the resale of this fixed demand at regulated retail prices. To the extent that LSEs are able to secure timely increases in these regulated retail prices in step with increases in wholesale prices, the LSEs are able to largely insulate themselves from the adverse consequences of higher LMP payments. In this case no direct participant in the wholesale power market suffers a loss of net surplus when LMPs increase due to congestion, fixed demand, and/or GenCo capacity withholding. Rather, losses in net surplus are borne by retail consumers. Moreover, barriers to entry into transmission, generation, and load servicing could then lead to the persistence over time of socially inefficient wholesale rents, i.e., wholesale net surplus collections in excess of the amounts needed to maintain resources in their current productive uses.

Power market researchers recognize that an important goal of market design is to ensure the alignment of participant objectives with socially desirable outcomes, thus reducing the need for oversight of participant behaviors [38]. The main conclusion drawn from the findings in this study is that ISO net surplus collections are not well-aligned with efficiency objectives in ISO-managed wholesale power markets operating under LMP because they increase in situations unfavorable to market efficiency. Moreover, the rules currently used to allocate ISO net surplus collections are not well-aligned with efficiency objectives because they do not provide an effective remedy for the underlying conditions inhibiting efficient market operation that result in high ISO net surplus collections.

These issues require further study. Particularly important will be investigations that test the robustness of our findings for larger-scale power systems, and that consider alternative wholesale power market designs with improved incentive alignments should robustness be affirmed.

However, an immediate step that could be taken is increased transparency and consistency in the public reporting of ISO financial operations, including ISO net surplus collections and allocations. Since the Enron disaster, and especially since the Energy Policy Act of 2005 [39] and the GAO report of 2008 [40], FERC has taken major steps to require increased reporting accountability by energy companies in accordance with generally accepted accounting principles (GAAP) [41]. Extension of these efforts to require fuller GAAP compliance by the not-for-profit ISOs would help to ensure better public accountability and easier cross-comparisons. This, in turn, would enable a more informed public debate regarding the extent to which ISOs are achieving just and reasonable outcomes for their market stakeholders and the public at large.

\section{APPENDIX A}

\section{DC-OPF PROBLEM FORMULATION}

The standard hourly bid/offer-based DC optimal power flow $(D C-O P F)$ problem formulation for an ISO-managed dayahead energy market involves the maximization on day D of reported total net surplus TNS $^{R}$ for a particular hour $\mathrm{H}$ of day D+1 subject to transmission and generation capacity constraints in approximate linear form [2]. Total net surplus refers to the sum of LSE, GenCo, and ISO net surplus. The qualifier "reported" indicates that the ISO must base its total net surplus calculation on LSE demand bids and GenCo supply offers rather than on their true purchase and sale reservation values, which are not directly observable by the ISO.

As detailed in [42], AMES(V2.05) solves this standard DCOPF problem via $D C O P F J$, a highly accurate and efficient DC-OPF module. DCOPFJ wraps a SI/pu data conversion shell around QuadProgJ, a quadratic programming (QP) solver that implements the well-known Goldfarb-Idnani dual active set QP algorithm.

The SI form of the standard DC-OPF problem implemented in the current study is outlined below making using of the notation and concepts introduced in Section II. In all treatments, the LSEs in AMES(V2.05) report their true purchase reservation values (1). Consequently, for no-learning treatments, the objective function TNS $^{R}$ coincides with true total net surplus (14) based on true purchase and sale reservation values. However, for GenCo learning treatments, $\mathrm{TNS}^{R}$ is based on reported GenCo sale reservation values (i.e., reported marginal costs) as given in (6) rather than on true GenCo sale reservation values (i.e., true marginal costs) as given in (8). 
DC Optimal Power Flow Problem:

$$
\max \operatorname{TNS}^{R}
$$

with respect to LSE real-power price-sensitive demands, GenCo real-power generation levels, and voltage angles

$$
p_{L j}^{S}, j=1, \ldots, J ; p_{G i}, i=1, \ldots, I ; \delta_{k}, k=1, \ldots, K
$$

subject to

(i) a real-power balance constraint for each bus $k=1, \ldots, K$ :

$$
\sum_{i \in I_{k}} p_{G i}-\sum_{j \in J_{k}} p_{L j}^{S}-\sum_{k m} P_{k m}=\sum_{j \in J_{k}} p_{L j}^{F}
$$

where, letting $x_{k m}$ (ohms) denote reactance for branch $\mathrm{km}$, and $V_{o}$ denote the base voltage (in line-to-line $k V$ ),

$$
P_{k m}=\left[V_{o}\right]^{2} \cdot\left[1 / x_{k m}\right] \cdot\left[\delta_{k}-\delta_{m}\right]
$$

(ii) a limit on real-power flow for each branch $\mathrm{km}$ :

$$
\left|P_{k m}\right| \leq P_{k m}^{U}
$$

(iii) a real-power operating capacity interval for each GenCo $i=1, \ldots, I$ :

$$
\operatorname{Cap}_{i}^{L} \leq p_{G i} \leq \operatorname{Cap}_{i}^{U}
$$

(iv) a real-power purchase capacity interval for price-sensitive demand for each LSE $j=1, \ldots, J$ :

$$
0 \leq p_{L j}^{S} \leq \operatorname{SLMax}_{j}
$$

(v) and a voltage angle setting at angle reference bus 1 :

$$
\delta_{1}=0
$$

This DC-OPF problem can be solved as a strictly concave quadratic programming problem either by using the bus balance constraints (18) to substitute out for voltage angles [2, Section 3.2] or by using an augmented Lagrangian method [30, p. 288] in which the objective function TNS $^{R}$ in (16) is augmented with a physically meaningful quadratic penalty term for the sum of squared voltage-angle differences to produce a strictly concave objective function with respect to all of the choice variables (17). The latter augmented Lagrangian approach is taken in AMES(V2.05). ${ }^{18}$

\footnotetext{
${ }^{18}$ The validity of DC-OPF dispatch and price solutions as approximations for AC-OPF dispatch and price solutions relies on the assumption that the voltage angle difference across each branch is small in magnitude [2]. As detailed in the working paper version of [42], the augmented Lagrangian DCOPF solution method implemented in AMES(V2.05) via DCOPFJ permits the accuracy of this assumption to be directly checked in any given application. In the current application, with a penalty weight set to 0.05 , the sum of squared voltage-angle differences indeed remained small in magnitude (about $10^{-2}$ ) throughout all experiments. Moreover, perturbations in this penalty weight resulted in no discernable effects on DC-OPF dispatch and LMP solutions through at least three decimal places.
}

The shadow price (Lagrange multiplier) solution for the real power balance constraint (18) at bus $k$, denoted by $\mathrm{LMP}_{k}$, constitutes the locational marginal price for bus $k$. By the well-known envelope theorem, $\mathrm{LMP}_{k}(\$ / \mathrm{MWh})$ measures the change in the maximized DC-OPF objective function $(\$ / \mathrm{h})$ with respect to a change in fixed demand (MW) at bus $k$; see [2] for a rigorous discussion. Stated less formally, $\mathrm{LMP}_{k}$ essentially measures the cost of efficiently servicing an additional MW of fixed demand at bus $k$.

\section{APPENDIX B \\ GenCo LEARning}

GenCo learning is implemented using a variant of a stochastic reinforcement learning algorithm developed by Roth and Erev ( [43], [44]) based on human-subject experiments, hereafter referred to as the VRE learning algorithm. The essential idea of stochastic reinforcement learning is that the probability of choosing an action should be increased (reinforced) if the corresponding reward is relatively good and decreased if the corresponding reward is relatively poor.

For the study at hand, a supply offer for any GenCo $i$ takes the form of a linear marginal cost function (6) that can be summarized by a vector $\mathrm{s}_{i}^{R}=\left(\mathrm{a}_{i}^{R}, \mathrm{~b}_{i}^{R}\right)$ determining its ordinate $\mathrm{a}_{i}^{R}$ and slope $2 \mathrm{~b}_{i}^{R}$. Each GenCo $i$ has available an action domain $A D_{i}$ consisting of a finite number of possible actions $s_{i}^{R}$ (supply offers). This action domain is tailored to GenCo $i$ 's own particular true cost and capacity attributes; e.g., it only contains marginal cost functions (6) lying on or above GenCo i's true marginal cost function (8) and it always contains GenCo $i$ 's true marginal cost function. However, the action domains are constructed so as to ensure equal cardinalities and similar densities across all GenCos to avoid favoring some GenCos over others purely through action domain construction. ${ }^{19}$

The remainder of this section describes how an arbitrary GenCo $i$ goes about using the VRE learning algorithm to select actions $\mathrm{s}_{i}^{R}$ from its action domain $\mathrm{AD}_{i}$ to submit to the ISO for the day-ahead energy market on successive days $\mathrm{D}$, starting from an initial day $\mathrm{D}=1$. As will be seen below, the only relevant attribute of $\mathrm{AD}_{i}$ for implementation of VRE learning is that it has finite cardinality. Consequently, letting $\mathrm{M}_{i} \geq 1$ denote the cardinality of $\mathrm{AD}_{i}$, it suffices to index the actions in $\mathrm{AD}_{i}$ by $m=1, \ldots, \mathrm{M}_{i}$.

The initial propensity of GenCo $i$ to choose action $m \in$ $A D_{i}$ is given by $\mathrm{q}_{i m}(1)$ for $\mathrm{m}=1, \ldots, \mathrm{M}_{i}$. AMES(V2.05) permits the user to set these initial propensity levels to any real numbers. However, the assumption used in this study is that GenCo $i$ 's initial propensity levels are all set equal to some common value $\mathrm{q}_{i}(1)$, as follows:

$$
q_{i m}(1)=q_{i}(1) \text { for all actions } m \in A D_{i}
$$

Now consider the beginning of any day $\mathrm{D} \geq 1$, and suppose the current propensity of GenCo $i$ to choose action $m$ in $\mathrm{AD}_{i}$ is given by $\mathrm{q}_{i m}(\mathrm{D})$. The choice probabilities that GenCo $i$ uses to select an action for day D are then constructed from

\footnotetext{
${ }^{19} \mathrm{~A}$ detailed explanation of this action domain construction can be found in [28, Appendix B].
} 
these propensities using the following commonly used GibbsBoltzmann transformation:

$$
p_{i m}(D)=\frac{\exp \left(q_{i m}(D) / T_{i}\right)}{\sum_{j=1}^{M_{i}} \exp \left(q_{i j}(D) / T_{i}\right)}, m \in A D_{i}
$$

In (24), $T_{i}$ is a temperature parameter that affects the degree to which GenCo $i$ makes use of propensity values in determining its choice probabilities. As $\mathrm{T}_{i} \rightarrow \infty$, then $\mathrm{p}_{i m}(\mathrm{D}) \rightarrow 1 / \mathrm{M}_{i}$, so that in the limit GenCo $i$ pays no attention to propensity values in forming its choice probabilities. On the other hand, as $\mathrm{T}_{i}$ $\rightarrow 0$, the choice probabilities (24) become increasingly peaked over the particular actions $m$ having the highest propensity values $\mathrm{q}_{i m}(\mathrm{D})$, thereby increasing the probability that these actions will be chosen.

At the end of day $\mathrm{D}$, the current propensity $\mathrm{q}_{i m}(\mathrm{D})$ that GenCo $i$ associates with each action $m$ in $\mathrm{AD}_{i}$ is updated in accordance with the following rule. Let $m^{\prime}$ denote the action actually selected and reported into the day-ahead market by GenCo $i$ in day D. Also, let $\mathrm{NE}_{i m^{\prime}}$ (D) denote the actual daily net earnings (11) attained by GenCo $i$ at the end of day D as its settlement payment for all 24 hours of the day-ahead market for day $\mathrm{D}+1$. Then, for each action $m$ in $\mathrm{AD}_{i}$,

$$
\begin{aligned}
& q_{i m}(D+1)=\left[1-r_{i}\right] q_{i m}(D)+\text { Response }_{i m}(D), \\
& \text { Response }_{i m}(D)= \begin{cases}{\left[1-e_{i}\right] \cdot N E_{i m^{\prime}}(D)} & \text { if } m=m^{\prime} \\
e_{i} \cdot q_{i m}(D) /\left[M_{i}-1\right] & \text { if } m \neq m^{\prime},\end{cases}
\end{aligned}
$$

where $^{20} r_{i} \in[0,1], e_{i} \in[0,1)$, and $m \neq m^{\prime}$ implies $\mathbf{M}_{i} \geq$ 2. The introduction of the recency parameter $r_{i}$ in (25) acts as a damper on the growth of the propensities over time. The experimentation parameter $\mathrm{e}_{i}$ in (26) permits reinforcement to spill over to some extent from a chosen action to other actions to encourage continued experimentation with various actions in the early stages of the learning process.

\section{ACKNOWLEDGEMENTS}

The authors are grateful to J. Lin, E. Litvinov, J. McCalley, R. O’Neill, A. Papalexopoulos, J. Price, P. Sircar, and four anonymous referees for helpful comments and pointers to data.

\section{REFERENCES}

[1] P. Joskow, "Markets for power in the United States: An interim assessment," The Energy Journal, vol. 27, no. 1, 1-36, 2006.

[2] H. Liu, L. Tesfatsion, and A. A. Chowdhury, "Derivation of locational marginal prices for restructured wholesale power markets," Journal of Energy Markets, vol. 2, no. 1, 3-27, 2009.

[3] L. Tesfatsion,"Auction basics for restructured wholesale power markets: Objectives and pricing rules," Proceedings of the IEEE Power and Energy Society General Meeting, Calgary, Alberta, CA, July 2009. www.econ.iastate.edu/tesfatsi/AuctionBasics.IEEEPES2009.LT.pdf

${ }^{20}$ In the original Roth-Erev algorithm, the term $q_{i m}(D)$ in (26) is instead given by $\mathrm{NE}_{i m^{\prime}}$ (D). However, as explained in [45], in this case there is no updating of propensities when net earnings outcomes are zero, e.g., due to a failure to be dispatched. This can result in prolonged mushing around in the early stages of learning when GenCos are trying to learn appropriate supply offers, with subsequent losses of net earnings and reductions in market efficiency. The substitution of $q_{i m}(D)$ for $\mathrm{NE}_{i m^{\prime}}$ (D) in equation (26), introduced in [45] to avoid this zero-updating problem, resulted in dramatic improvements in both GenCo net earnings and in market efficiency.
[4] E. Hausman, R. Fagan, D. White, K. Takahashi, and A. Napoleon, "LMP electricity markets: Market operations, market power, and value for consumers," Synapse Energy Economics, February 2006.

[5] G. Gross and E. Bompard, "Optimal power flow application issues in the pool paradigm," Elect. Pow. and Energy Sys., vol. 26, 787-796, 2004.

[6] D. Kirschen and G. Strbac, Fundamentals of Pow. Econ., Wiley, 2004.

[7] A. Somani and L. Tesfatsion, "An agent-based testbed study of wholesale power market performance measures," IEEE Computational Intelligence Magazine, vol. 3, no. 4, 56-72, 2008.

[8] G. B. Aldete, "Alternative models to analyze market power and financial transmission rights in electricity markets," Ph.D. Thesis, Department of Electrical and Comp. Eng. U. of Waterloo, Ontario, 2005.

[9] H. Li and L. Tesfatsion, "The AMES wholesale power market testbed: A computational laboratory for research, teaching, and training," Proceedings of the IEEE Power and Energy Society General Meeting, July 2009. www.econ.iastate.edu/tesfatsi/AMESTestBed.2009IEEEPESGM.pdf

[10] Transmission Economic Assessment Methodology, California Independent System Operator (CAISO), June 2004. www.caiso.com/docs/2004/ 06/03/2004060313241622985.pdf

[11] H. Liu, Y. Shen, Z. Zabinsky, C.C. Liu, A. Courts, and S.K. Joo, "Social welfare maximization in transmission enhancement considering network congestion", IEEE Trans. Pow. Sys., vol. 23, 1105-1114, 2008.

[12] R. Walawalkar, S. Blumsack, J. Apt, and S. Fernands, "An economic welfare analysis of demand response in the PJM electricity market," Energy Policy, vol. 36, 3692-3702, 2008.

[13] S. Oren and G. Gross, "Economic impact assessment of transmission enhancement projects," Final Report, PSERC Publication 09-07, September 2009.

[14] L. L. Kiesling, "The role of retail pricing in electricity restructuring," pp. 39-62 in A. N. Kleit, Electric choices: Deregulation and the future of electric power, Rowman \& Littlefield, NY, 2007.

[15] FERC, Assessment of demand response and advanced metering, Staff Report, Federal Energy Regulatory Commission, December 2008.

[16] "The choice is yours: Demand response," IEEE Power and Energy Society Magazine, vol. 8, no. 3, May/June 2010.

[17] S. Raikar and M. Ilić, "Assessment of transmission congestion for major electricity markets in the US," MIT EL 01-009 Working Paper, Energy Laboratory, MIT, February 2001.

[18] M. Dworkin and R. Goldwasser, "Ensuring consideration of the public interest in the governance and accountability of regional transmission organizations," Energy Law J., vol. 28, no. 2, 543-601, 2007.

[19] AMES Wholesale Power Market Testbed Homepage www.econ.iastate. edu/tesfatsi/AMESMarketHome.htm

[20] IEEE Task Force on Open Source Software for Power Systems ewh.ieee.org/cmte/psace/CAMS_taskforce/index.htm

[21] MISO, Energy and Operating Reserve Markets, Business Practices Manual No. 002, Effective Date: January 6, 2009.

[22] MISO, Energy Market Instruments, Business Practices Manual No. 003 , Effective Date: April 1,2008.

[23] ISO-NE, Market Operations, ISO New England Inc., Revision: 32, Effective Date: July 1, 2009.

[24] R. Baldick and W. Hogan, "Capacity constrained supply function equilibrium models of electricity markets: Stability, non-decreasing constraints, and function space iterations," University of California Energy Institute PWP-089, Aug. 2002. www.ucei.berkeley.edu/ucei/PDF/pwp089.pdf

[25] R. Baldick, R. Grant, and E. Kahn, "Theory and application of linear supply function equilibrium in electricity markets," Journal of Regulatory Economics, vol. 25(2), pp. 143-167, 2004.

[26] H. Salazar, A critical appraisal of economic-driven transmission enhancement, M.S. Creative Component, ISU Econ. Dept., Nov. 2008.

[27] T. Orfanogianni and G. Gross, "A general formulation for LMP evaluation," IEEE Trans. Pow. Sys., vol. 22, no. 3, pp. 1163-1173, 2007.

[28] H. Li, J. Sun, and L. Tesfatsion, "Separation and volatility of locational marginal prices in restructured wholesale power markets," ISU Economics Working Paper \#09009, June 2009. www.econ.iastate.edu/ research/publications/viewabstract.asp?pid $=13075$

[29] J. Lally, "Financial transmission rights: Auction example," Section 6 in Financial Transmission Rights Draft 01-10-02, m-06 ed., ISO New England, Inc., January 2002.

[30] M. Shahidehpour, H. Yamin, and Z. Li, Market Operations in Electric Power Systems, New York, NY: IEEE/Wiley-Interscience, 2002.

[31] PJM, 2008 State of the Market Report, Vol. 2: Detailed Analysis, Monitoring Analytics, LLC, Independent Market Monitor for PJM, March 11, 2009. www.monitoringanalytics.com/reports/PJM_State_of_ the_Market/2008/2008_som-pjm_volume2.pdf 
[32] MISO, 2008 State of the Market Report for the Midwest ISO, Potomac Economics, Independent Market Monitor for the Midwest ISO, July 21, 2009. www.midwestiso.org/publish/Document/

[33] ISO-NE, 2008 Annual Markets Report in ISO New England, Independent Market Monitoring Unit, ISO New England, Inc., June 2009. www. iso-ne.com/markets/mktmonmit/rpts/other/amr08_final_061709.pdf

[34] CAISO, Market Issues \& Performance, 2008 Annual Report, Department of Market Monitoring, California Independent System Operator Corporation, April 2009. www.caiso.com/2390/239087966e450.pdf

[35] H. Liu, Myth of locational marginal price unleashed, M.S. Economics Creative Component, Iowa State University, May 2008.

[36] E. Litvinov, F. Zhao, and T. Zheng, "Alternative auction objectives and pricing schemes in short-term electricity markets," Proceedings of the IEEE Power and Energy Society General Meeting, Calgary, Canada, July 2009.

[37] R. Benjamin, A further inquiry into FTR properties, Report, Round Table Group, Inc., February 2010.

[38] E. Sauma and S. Oren, "Do generation firms in restructured electricity markets have incentives to support social-welfare-improving transmission investments?", Energy Economics, vol. 31, 676-689, 2009.

[39] Energy Policy Act of 2005, Public Law 109-58, 109th Congress, August 8, 2005. http://www.epa.gov/oust/fedlaws/publ_109-058.pdf

[40] GAO, Electricity restructuring: FERC could take additional steps to analyze regional transmission organizations' benefits and performance, United States Government Accountability Office Report to the Committee on Homeland Security and Governmental Affairs, U.S. Senate, GAO-08-987, September 2008.

[41] M. Lewis, FERC compliance: A legal and business guide, Morgan, Lewis \& Bockius LLP, Washington, D.C., 2009.

[42] J. Sun and L. Tesfatsion, "Open-source software for power industry research, teaching, and training: A DC-OPF illustration," Proceedings of the IEEE Power and Energy Society General Meeting, Tampa, Florida, June 2007. Working Paper Version: www.econ.iastate.edu/ tesfatsi/DC-OPF.JSLT.pdf

[43] A. E. Roth and E. Ido, "Learning in extensive form games: Experimental data and simple models in the intermediate term," Games and Economic Behavior, vol. 8, pp. 164-212, 1995.

[44] I. Erev and A. E. Roth, "Predicting how people play games with unique mixed-strategy equilibria," American Economic Review, vol. 88, pp. 848-881, 1998.

[45] J. Nicolaisen, V. Petrov, and L. Tesfatsion, "Market power and efficiency in a computational electricity market with discriminatory double-auction pricing," IEEE Transactions on Evolutionary Computation, vol. 5, no. 5, October 2001, pp. 504-523.

Hongyan Li received his M.S. degree in Electric Power Systems from Xi'an Jiaotong University (China) in 1997 and worked as an engineer for the Sifang \& Huaneng Power System Control Corporation (China) for seven years. In December 2009 he received his Ph.D. degree in Electrical and Computer Engineering from Iowa State University, and in January 2010 he joined ABB Inc. (North Carolina) as an Engineering Consultant. His principal research area is power system economics, with a particular focus on the efficiency and reliability of restructured wholesale power markets.

Leigh Tesfatsion received her Ph.D. in Economics from the University of Minnesota in 1975. She is Professor of Economics, Mathematics, and Electrical and Computer Engineering at Iowa State University. Her principal research area is agent-based testbed development, with a particular focus on restructured electricity markets. She is an active participant in various IEEE PES committees focusing on power economics issues and a co-organizer and director of the ISU Electric Energy Economics (E3) Group. She serves as associate editor for a number of journals, including J. of Energy Markets. 